\title{
Employment for Sustainable Development: Sectoral Efficiencies in EU Countries
}

\author{
Magdalena Cyrek ${ }^{1} \cdot$ Barbara Fura $^{1}$
}

Accepted: 11 July 2018 / Published online: 17 July 2018

(c) The Author(s) 2018

\begin{abstract}
Measuring sustainable development requires multidimensional attitude as the process is characterised by compound relationships between social, economic and environmental spheres. The paper aims at assessing selected effects of sectoral employment for the three dimensions of developmental processes. We examine employment efficiency in $25 \mathrm{EU}$ countries concerning four sectors: agriculture, industry, market services, and non-market services. We use a non-radial DEA input-oriented model, which allows the assessment of the general efficiency of labour resources, as well as the evaluation of in-depth efficiency in the three dimensions of the economies under study. The novelty of the research lays in both multidimensional attitudes to the effects of labour engagement as well as intersectoral comparisons of the employment results. We categorise the EU countries according to efficiency in gaining the sustainable development and its three dimensions. Generally, the "old" EU members are of higher efficiency than the "new" states. Our research shows desirable movements of labour force that are necessary to improve efficiency and thus offers some advice for a rational development policy. It appears that it is necessary to limit agricultural employment in favour of non-market and market services and, to a lower extent, of industry. We conclude that the structural changes in employment specified by patterns observed in the highly developed EU countries are favourable for realising the aims of sustainable development.
\end{abstract}

Keywords Sustainable development $\cdot$ Economic sectors $\cdot$ Labour productivity $\cdot$ DEA

JEL Classification $\mathrm{O} 11 \cdot \mathrm{O} 20$

Barbara Fura

bfura@ur.edu.pl

Magdalena Cyrek

mcyrek@ur.edu.pl

1 Faculty of Economics, University of Rzeszów, Ćwiklińskiej 2, 35-601 Rzeszów, Poland 


\section{Introduction}

Mainstream economics perceives labour productivity as the main problem in understanding economic evolution. It is considered as a driving force of economic growth and is often analysed in terms of convergence or national competitiveness (e.g. Demeter et al. 2011; Misiak et al. 2011; Piętak 2014). Generally, productivity is defined as the relationship between outputs and inputs, and in economics, it is considered as the relationship between production and the factors of production. Against this background, labour productivity is equal to the ratio between a volume measure of output (gross domestic product (GDP) or gross value added) and a measure of input use (the total number of hours worked or total employment) (Freeman 2008). As many economists stress, labour productivity depends on the availability and quality of labour resources, applied technologies (Auzina-Emsina 2014), capital accumulation (Ceccobelli et al. 2012) and innovation (Kurt and Kurt, 2015). We assume that the sectoral structure of an economy constitutes another important factor influencing labour productivity. Some sectors are able to generate better results than others and thus labour shifts can either increase or decrease the general efficiency of a country.

Nevertheless, labour productivity is usually analysed at an aggregate level of the economy and the number of studies concerning intersectoral differences in labour productivity is limited. In this relatively neglected field of research the recent studies by Bernard and Jones (1996), Maudos et al. (2000), Carree et al. (2000), Lee (2005), Wong (2006), Badunenko and Romero-Ávila (2014, 2015), O'Leary and Webber (2015), Martino (2015) or Kosmalski (2016) are an exception. They have their roots in classical research on structural development started in the $1930 \mathrm{~s}$ by Fisher (1935), Clark (1940) and next by Fourastié (1949) in their three-sectoral concepts of socio-economic development. The search for a sectoral growth pole was present in the works of Perroux (1955), in Hirschman's (1958) ideas of an unbalanced development, as well as in Rostow's (1971) studies of economic development. This disaggregated attitude led researchers to compare the economic performance of different parts of the economy. The sectoral approach is adopted in this study, where we consider the efficiency of four sectors: agriculture, industry, market services and non-market services.

Another important issue connected with analyses of labour productivity is specified by the definition of outputs, which can be defined as the desired results of a labour engagement expected to increase national welfare. The mainstream of research that covers international comparisons of levels of development is focused on its economic dimension specified by GDP per capita. Although production and income, however, are undoubtedly the most important determinants of the general level of development, there are other essential factors strongly influencing the welfare of nations. In a framework of sustainable development (SD), these are specified as social and environmental dimensions and complement the economic dimension (e.g. Galdeano-Gómez et al. 2016; Islam et al. 2003). A broad concept of an integrated holistic development assumes that different dimensions of human nature must be balanced and man cannot be viewed solely as homo oeconomicus (Woźniak et al. 2015).

In the literature, as well as in a political debate, SD is concerned with finding a way whereby human socio-economic needs can be met in a harmony with environmental issues, given their strong interdependence (Bolis et al. 2017). The economy view in SD is geared mainly towards improving human welfare, primarily through increases in goods and services consumption. The environmental domain focuses on an integrity protection and a resilience of ecological systems. The social domain emphasises an enrichment of human 
relationships and an achievement of individual and group aspirations (Islam et al. 2003). The concept of SD covers the issue of intergenerational balance in human well-being described as 'meeting the needs of the present without compromising the ability of future generations to meet their own needs' (Our Common Future 1987). It adopts an inclusive wealth theory that assumes that development is sustainable if society's productive base per capita does not decline over time, and the ability of future generations to meet their own needs is not disrupted (Collins et al. 2017).

In this vein, it is stressed that it is complexity what is required when measuring wellbeing (Maggino and Zumbo 2012). Nevertheless, because of some essential problems with an operationalisation of SD goals, there still exists a research gap in an assessment of labour productivity described by results of human resources engagement for different spheres of development. Thus, discussing issues of SD we adopt a three-dimensional approach and simultaneously consider social, economic and environmental objectives shaping employment structures. Our study connects a labour productivity issue with the concept of SD and perceives productivity as an indicator of the development.

The aim of the paper is to identify the most efficient structures of employment that are able to generate positive results in the three dimensions of SD. The comparisons are made considering European Union (EU) countries as relatively homogenous economies in terms of socio-economic development and its institutional conditions. In order to indicate the most efficient countries within the EU that can be perceived as structural benchmarks, as well as to specify intersectoral differences in the social, economic and environmental effects of employment, a non-radial data envelopment analysis (non-radial DEA) method was used.

The DEA method allows a relative efficiency assessment of selected decision-making units (DMU) on a background of reference units in a given area of an analysis. In this paper, it is the productivity of employment of selected EU countries. The advantage of the DEA usage stems from its feature as a method that does not require the specification of any particular functional form of relationships between multiply outputs and inputs as well as a money value to aggregate an information. Moreover, this method advantage is connected with the possibility to avoid a problem of the aggregate level of analysis. As different sectors may characterise different levels of efficiency in a process of SD, an aggregate approach may significantly influence the results. The use of non-radial DEA allows to estimate not only the overall productivity of employment, as an average of the productivity of each economic sector i.e. agriculture, industry, services (market and non-market), but also to define necessary shifts of labor resources within sectors. Because the use of appropriate instruments of economic policy may have a great impact on the allocation of labor resources within sectors and shifts of resources from less efficient sectors to those with higher efficiency, therefore the study uses the input-oriented DEA model. Its application allows the assessment of both the general three-dimensional efficiency of employment structures among EU countries and the separate analysis of each dimension of SD, concerning all employment inputs. In this paper, we test the following research hypothesis:

H The structural modernisation of the "new" member states that follows a pattern typical of the "old" EU countries may enhance their efficiency in terms of social, economic and environmental dimensions of SD.

The rest of the paper is organised as follows. Section 2 presents a literature review on interrelations among dimensions of SD in the context of overall productivity improvement. 
Section 3 briefly describes the research method used, i.e. radial and non-radial CCR model and a concept of canonical correlations as a basis for variables selection. Section 4 presents the first part of research findings, namely data and variables, descriptive statistics, canonical correlations results, as well as a general condition of labour markets in the EU countries. Section 5 presents and discusses an overall efficiency of employment in the examined sectors and the detailed efficiencies namely social, economic and environmental of the studied EU's member states. The concluding section ends the paper with summaries, general findings, and practical recommendation.

\section{Literature Review}

Undertaking research in the field of sectoral employment efficiencies, taking into account economic, social and environmental areas of SD, required a double-track approach to the literature review. Firstly, in terms of a role and importance of these areas for the growth and economic development. Secondly, in terms of a role and significance of a productivity, as one of the features of SD strengthening convergence of regions and countries. Among the referenced works, there are both review papers and papers attempting to empirically assess productivity, in particular, the productivity of employment, including works using DEA method.

Strong interrelations among the SD dimensions are highlighted by many researchers. A starting point for such research can be found in the works of Kuznets (1955), who formulated a hypothesis about a relationship between economic development and income inequalities in a form of an inverted U-shaped curve (the Kuznets curve (KC) phenomenon). The KC is traditionally explained by Lewis's two-sector model, in which a shift from agriculture to industry decreases inequality. In a phase of digitalisation, however, some authors point out that the disparities grow again (Kiatrungwilaikun and Suriya 2015). Moreover, research in the developing world has proved that the relationship between inequalities and structural change may differ depending on the different phases of structural development (Andersson and Palacio 2016).

Grossman and Krueger (1995) established that the same inverted U-shaped pattern describes a relationship between economic development and environmental degradation (the environmental Kuznets curve (EKC) phenomenon). Concerning the EKC, structural changes specified by industrialisation are associated with environmental deterioration, while increasing de-industrialisation is characterised by lower environmental degradation. Structural changes from agriculture-based economies to industrial and services ones are specified as a basic explanation for the EKC hypothesis by Charfeddine and Mrabet (2017).

In fact, the $\mathrm{KC}$ and EKC relationships are not fully validated and some authors neglect their existence in the specified form (e.g. Dinda 2004; Kiatrungwilaikun and Suriya 2015; Nasr et al. 2018). Explanations for both, however, are connected with sectoral changes within the economy. They are stimulated by differences in the sectoral efficiency of resource usage, as well as changing social preferences in consumption and a new lifestyle. Thus, one of important issues specifying development lays in the productivity understood as a ratio between outputs and inputs.

As the main issue connected with the development is an increase in productivity, many authors analyse an aggregate production efficiency and its changes over time. They try to find explanations for a convergence between national and regional economies. Ahmed and Krishnasamy (2013) conducted DEA for productivity changes in ASEAN countries to 
found its main sources. Ko Li and Zhao (2015) explored a DEA model to discuss the possible strategies of Chinese provinces to improve their competitiveness, which the authors strongly connect with real GDP per capita. Gitto and Mancuso (2015) used a DEA model to decompose changes in labour productivity in Italy in the context of regional differences.

The analysis of labour productivity growth, however, is typically conducted by adopting an aggregate approach to different kinds of economic activity. Some exceptions include work conducted by Maudos et al. (2000), who, while assessing the efficiency of production and regional convergence in Spain, used a 5-sectoral disaggregation specifying: agriculture, industry (excluding energy), energy, construction, and services. As a result, they differentiated between two components of efficiency in aggregate production: intra-sector efficiency and efficiency of the composition of production. Badunenko and Romero-Ávila (2015) proposed a similar approach to sectoral disaggregation. They attempted to discover the sources of labour productivity growth in 5 sectors in Spain i.e. agriculture, energy, manufacturing, construction, and services. Both Maudos et al. (2000) and Badunenko and Romero-Ávila $(2014,2015)$ came to a conclusion that there are essential differences in sectoral performance. While Badunenko and Romero-Ávila (2014, 2015), however, claimed that aggregate productivity growth is mainly driven by intrasectoral productivity dynamics rather than structural change (sectoral shifts), Maudos et al. (2000) underlined greater gains in composed efficiency as a consequence of structural changes. O'Leary and Webber (2015) presented research results for European regions that rehabilitate the importance of structural change for growth and convergence. They asserted that inter-sectoral structural change appeared to be especially important for those regions situated towards the higher deciles of distribution.

Simultaneously, researchers are trying to specify which sectors are the main drivers of modern development and convergence between nations and regions. Wong (2006) showed that while productivity growth in services and agriculture contributed significantly to OECD convergence, the contributions from employment shift and productivity growth in manufacturing were not statistically significant. Lee (2005) pointed out that for the productivity growth of the Korean economy there is a great need for productivity improvement in services. The above results are in line with Bernard and Jones (1996), who examined the role of sectors in aggregate convergence for 14 OECD countries. Their major finding showed a driving force of services and the diminishing effect of manufacturing in the aggregate convergence process. In the same vein, Carree et al. (2000), while analysing labour productivity across manufacturing industries in 18 OECD countries, showed large inter-industry differences in the extent of convergence. These were explained by a differentiation in a level of average labour productivity. The labour productivity dynamics of the EU during 1991-2007 were investigated by Martino (2015). Despite the generally conditional character of the convergence process, he revealed an unconditional convergence process for financial and business-related market services. Such a convergence was not confirmed for manufacturing and aggregated productivity. A regional analysis of convergence in Poland was presented by Kosmalski (2016). Using DEA approach he compared labour productivity growth among agriculture, industry and service sectors, indicating that their sources were mainly rooted in a technological progress and a capital accumulation. The author stressed that a structural modernisation of the converging economy is important, as it allows the reallocation of labour into the most efficient sectors. The importance of labour productivity was also stressed by Tarancón et al. (2018) who presented the results of a panel data analysis from 1995 to 2011. They examined a relationship between labour productivity and a degree of production efficiency for $24 \mathrm{EU}$ countries. Their results based on the DEA and a regression analysis confirmed the existence of a direct and significant 
relationship between labour productivity and production efficiency. According to them the observed relationship is also relevant from a policymaking point of view. The context of structural relations stresses a relevance of the service sector as the one contributing to the improvement of an overall efficiency in economy.

Existing literature provides a broad number of results on an efficiency assessment of the individual industry, service or agriculture sectors based on the DEA method. For example, Nazarko and Chodakowska (2015) used the method to examine the construction sector productivity in 25 European countries. Their analysis covered 2006-2012 period and revealed huge differences in productivity of construction industry within the EU countries. DEA method was also used to estimate the efficiency of a power generation sector in the USA (Halkos and Polemis 2018). Apart from the efficiency assessment, the study examined a relationship between environmental efficiencies and economic growth in attaining sustainability. Djordjević et al. (2018) employed a non-radial DEA model for an evaluation of railway efficiency of European countries regarding a level of safety at railway level crossings. Laurinavičius and Rimkuvienè (2017) using DEA provided results on the analysis of agricultural sectors efficiency of 28 EU member states (for 2010-2014). According to their results the agriculture sector of the "new" EU countries is still poorly effective, even though the efficiency tends to increase.

Despite numerous research results on the efficiency of individual branches, sectors or industries, there is still a limited number of studies that would comprehensively examine efficiencies of employment of entire economies, including their cross-sectoral relations. Moreover, their discussion does not exactly imply regarding how to improve the efficiency of sectors, organizations or other public and private entities as well as do not provide methodological guidance on how to achieve this in the context of SD.

Summing up the first step of the literature review, it is worth stressing that as all dimensions of human existence are interrelated, higher productivity, both within sectors and by shifting to sectors that generate higher value-added and yield benefits to workers, employers and the economy, is necessary to achieve sustained economic growth (World Development Indicators 2016). This idea led us to assess sectoral results for SD within EU countries.

Secondly, DEA has proven to be a useful tool for assessing productivity of entities which is of vital practical importance in managerial decision making (Park 2010). DEA is also widely considered as a technique to examine the level of efficiency and thus sustainability. Therefore, it is very important to carefully use DEA for guiding large policy issues such as an employment policy. This study may help to solve problems of low labour productivity by linking it with political efforts.

\section{Methods}

DEA is a method that allows relative technical efficiencies evaluation of a set of comparable entities, which use multiple inputs to produce multiple outputs. It uses linear programming (LP) techniques, in which a measurement of efficiency is defined as a ratio between the weighted sum of outputs and inputs. Analysed entities are usually called decision-making units (DMUs) (Poveda 2011). All DMUs are homogeneous, which means that they have the same types of inputs and outputs, and are independent, i.e. no constraint binds input and output levels of one DMU with inputs and outputs of another (Castelli et al. 2010). DMUs efficiency is measured in terms of radial or non-radial distance from the best unit on the 
production frontier, which is defined by the production function of the efficient units (Jain and Natarajan 2015).

\subsection{CCR Model}

Let us assume that there are $n$ DMUs to be evaluated. Each DMU consumes a different amount of $m$ inputs to produce $s$ outputs. This means that $j$ th DMU $(j=1, \ldots, n)$ consumes $x_{i j}$ of inputs $(i=1, \ldots, m)$ to produce $y_{r j}$ of outputs $(r=1, \ldots, s)$. We also assume that inputs $x_{i j}$ and outputs $y_{r j}$ are non-negative and each DMU has at least one positive input and one positive output. Thus, the efficiency of DMUs $\left(\theta_{j}\right)$ is defined by the formula:

$$
\theta_{j}=\frac{\sum_{r=1}^{s} u_{r} y_{r j}}{\sum_{i=1}^{m} v_{i} x_{i j}}
$$

where $u_{r}(r=1, \ldots, s)$ and $v_{i}(i=1, \ldots, m)$ are weights assigned to the $r$ th output and the $i$ th input respectively. In order to find the efficiency of $j$ th DMU relative to other DMUs, Charnes et al. (1978) developed the following well-known CCR model, which measures the best relative efficiency of DMUs. This mathematical programming model is described by (2)-(4)

$$
\begin{gathered}
\max \theta_{o}=\frac{\sum_{r=1}^{s} u_{r} y_{r o}}{\sum_{i=1}^{m} v_{i} x_{i o}} \\
\text { subject to } \frac{\sum_{r=1}^{s} u_{r} y_{r o}}{\sum_{i=1}^{m} v_{i} x_{i o}} \leq 1, \\
u_{r}, v_{i} \geq 0 \quad r=1, \ldots, s ; \quad i=1, \ldots, m,
\end{gathered}
$$

where $u_{r}$ and $v_{i}$ are decision variables. By $o \in\{1, \ldots, n\}$ we denote the index of $\mathrm{DMU}_{j}$ to be currently evaluated. Formula (2) without additional restrictions (3-4) has an infinite number of solutions. Condition (3) which means, that the ratio of outputs to inputs must be less than or equal to 1 , satisfies the normalized value of the efficiency measure of a given DMU (in the interval of $(0.1>)$ ). (4) ensures non-negative sign of the calculated weights of decision variables.

With the application of the Charnes and Cooper (1962) transformation, the above programming problem can be reduced to the linear form which is usually easier to solve and to interpret. In a case of an input-oriented model this form is determined by (5)-(8) formulas (Cooper et al. 2011):

$$
\begin{gathered}
\max \theta_{o}=\sum_{r=1}^{s} u_{r} y_{r o} \\
\text { subject to } \sum_{r=1}^{s} u_{r} y_{r o}-\sum_{i=1}^{m} v_{i} x_{i o} \leq 0,
\end{gathered}
$$




$$
\begin{gathered}
\sum_{i=1}^{m} v_{i} x_{i o}=1, \\
u_{r}, v_{i} \geq 0 \quad r=1, \ldots, s ; i=1, \ldots, m .
\end{gathered}
$$

In a case of an output-oriented model the linear programming problem (2)-(4) is defined by (9)-(12) formulas (Cooper et al. 2011):

$$
\begin{gathered}
\min \theta_{o}=\sum_{r=1}^{s} u_{r} y_{r o} \\
\text { subject to } \sum_{r=1}^{s} u_{r} y_{r o}-\sum_{i=1}^{m} v_{i} x_{i o} \geq 0, \quad j=1, \ldots, n, \\
\sum_{i=1}^{m} v_{i} x_{i o}=1, \\
u_{r}, v_{i} \geq 0 \quad r=1, \ldots, s ; i=1, \ldots, m .
\end{gathered}
$$

The CCR model presented above is further transformed into a dual linear programming (DLP) problem (e.g. Cooper et al. 2011). Considering the input-oriented model, a solution of the dual problem is to find a minimum value $\theta_{o}^{*}$, which allows such a reduction in inputs, so that a level of outputs remains unchanged. In turn, having the output-oriented model, the solution is to find a maximum value $\theta_{0}^{*}$, which allows to increase outputs, with an unchanged level of inputs. DMUo is CCR-efficient if $\theta_{o}^{*}=1$ and there exists at least one optimal $\left(v^{*}, u^{*}\right)$, with $v^{*}>0$ and $u^{*}>0$. Otherwise, DMUo is CCR-inefficient. Thus, CCRinefficiency means that either $\theta_{o}^{*}=<1$ or $\theta_{o}^{*}=1$ and at least one element of $\left(v^{*}, u^{*}\right)$ is zero for every optimal solution of LP.

The assessment of a DMU's efficiency is based upon 'oriented' measure of distance, which identifies a point on the isoquant of the technology with the same mix of inputs (input orientation) or outputs (output orientation) of the evaluating DMU. The constancy of this mix in movements toward the boundary of the technology is the characteristic that gives a radial measure (Aparicio et al. 2018), which optimises all inputs or outputs of DMU at a certain proportion.

\subsection{NR-CCR Model}

Considering that most of production processes, however, have multiple inputs and outputs, radial DEA modeling does not provide information on the efficiency of specific inputs or outputs (Hernández-Sancho et al. 2011). In order to solve this problem, Färe and Lovell (1978) proposed a measure of non-radial efficiency, known as the Färe-Lovell or Russell measure. 
The starting point for non-radial efficiency models is the abandonment of the uniform multiplier for all inputs/outputs. We assumed $\theta$ as the input multiplier and $\phi$ as the output multiplier. Thus, the formulation of the input/output oriented NR-CCR model (Guzik 2009; Zhou et al. 2008) we presented in Table 1.

(13) and (18) formulas stand for the objective function, which in the case of input/ output-oriented model is minimization/maximization of a mean of multipliers of inputs/ outputs respectively. (14), (15) and (19), (20), are limiting conditions in both models. In turn, formulas (16), (17) and (21), (20) represent sign constraints. The optimal value of (13), (18) is the arithmetic mean of the partial efficiencies of inputs and outputs. Since each partial efficiency is from the interval $(0,1>$, their arithmetic mean has the same property. The DMU is evaluated as efficient if and only if all its partial efficiencies are equal to one (Halická and Trnovská 2018). The optimal solution i.e. the Russell measure provides an average efficiency score, which is non-radial as it considers different contraction/expansion factors of inputs/outputs. Among other important properties, Färe and Lovell (1978) argued that the Russell efficiency measure satisfies the indication property, meaning that it is equal to 1 if and only if the assessed unit lies on a Pareto-efficient part of the frontier (Conceicao et al. 2006). A non-radial efficiency measure usually has a higher discriminating power than the radial efficiency measure (Zhou et al. 2008). However, the most important feature of Russell efficiency is the possibility of substitution of inputs/outputs because non-radial DEA doesn't assume any proportionality between inputs/outputs. Considering this feature, the current paper uses NR-CCR model to examine sectoral efficiencies of the selected DMUs.

\subsection{The Concept of Canonical Analysis}

The choice of inputs and outputs for the DEA is usually based on the researcher's experience. This approach, however, is risky involving potential losses in the information about relationships between variables, distortion in the perception of the researched phenomena or sketchy information about the essence of the relationships. In order to avoid such problems, as Sengupta (1990) proposed, we applied a canonical correlation analysis (CCA).

This enables the examination of relationships between two groups of variables allowing the researcher to assess the extent to which variables from the first group explain the range of variety of variables from the second group. The main idea involves the research of two

Table 1 Non-radial CCR models

\begin{tabular}{lll}
\hline Input-oriented model & \multicolumn{3}{c}{ Output-oriented model } \\
\hline $\min \left(\frac{1}{m} \sum_{i=1}^{m} \theta_{i j_{0}}\right)$ & $(13)$ & $\max \left(\frac{1}{s} \sum_{i=1}^{s} i j_{0}\right)$ \\
$\sum_{j=1}^{n} \lambda_{j} x_{i j} \leq \theta_{i j_{0}} x_{i j_{0}}$ & $(14)$ & $\sum_{j=1}^{n} \lambda_{j} y_{i j} \geq_{i j_{0}} y_{i j_{0}}$ \\
$\sum_{j=1}^{n} \lambda_{j} y_{i j} \leq y_{i j_{0}}$ & & $\sum_{j=1}^{n} \lambda_{j} x_{i j} \leq x_{i j_{0}}$ \\
$\theta_{i j_{0}} \leq 1$ & $(15)$ & $\phi_{i j_{0}} \geq 1$ \\
$\theta_{i j_{0}}, \lambda_{j} \geq 0$ & $(17)$ & $\phi_{i j_{0}}, \lambda_{j} \geq 0$
\end{tabular}

where $\theta_{i j_{0}}$-efficiency coefficient of $j_{0}$ th DMU with respect to the $i$ th input, $\phi_{i j_{0}}$-efficiency coefficient of $j_{0}$ th DMU with respect to the $i$ th output, $\lambda_{j}$-intensity level of $j$ th object technology in the common technology, $i=1, \ldots, m$-inputs, $j=1, \ldots, n-\mathrm{DMU}, r=1, \ldots, s-$ outputs 
groups of variables $\left\{\mathrm{X}_{1}, \mathrm{X}_{2}, \ldots, \mathrm{X}_{\mathrm{n}}\right\}$ and $\left\{\mathrm{Y}_{1}, \mathrm{Y}_{2}, \ldots, \mathrm{Y}_{\mathrm{m}}\right\}$ in order to analyse relationships between "hidden variables". New "hidden" variables are a type of compound indicator that measures "correlation" between the groups, and they are the weighted sum of the variables from both groups in the form of $a_{1} X_{1}+a_{2} X_{2}+\cdots+a_{n} X_{n}$ and $b_{1} Y_{1}+b_{2} Y_{2}+\cdots+b_{m} Y_{m}$. The CCA determines the optimal weights that maximise the correlation between the linear combination of variables (Friedman and Sinuany-Stern 1997). In this study it was used to examine the relationships between outputs and inputs.

\section{Results: A General Background of the EU Countries' Sustainable Development}

\subsection{Data and Variables}

Application of the NR-CCR DEA model requires specification of both the DMUs, as well as the variables used for an efficiency assessment. In this paper, labour efficiency in agriculture, industry, market and non-market service sectors was examined for 25 EU countries. Three member states (Luxembourg, Malta, and Cyprus) were excluded from the research as the DEA method assumes that the objects under evaluation should be homogeneous as much as possible. Luxembourg is characterised by a much higher level of GDP per capita than the EU average. It is a highly developed country with a prevailing service share in the economy (70\% of GDP), with especially high value added for the finance sector. Malta, like Luxembourg, may be specified as a country with a predominantly services share in the economy (75.2\%), with a special role of tourism. This feature is shared with Cyprus, along with the fact that these island states are among the smallest in the world (with a population of about 500 thousand). These countries are often perceived as tax havens, which may influence their economic results considerably. The selection of the countries could disturb the results of the research if the assumption of the homogeneity of objects is not fulfilled.

Empirical data describing the states under study were extracted from the Eurostat database (http://ec.europa.eu/eurostat). In order to describe results in the SD process, three variables representing each dimension, i.e. social, economic and environmental, were used. Social achievements are related to a harmonised and egalitarian society and are manifested through a low level of income inequality. The income quintile share ratio is one of the most widely known. As the output indicator is expected to increase when the object performs well, the reversed measure is used. The most cohesive society is characterised by the highest (close to 1) $\mathrm{O}_{1}$ variable, as the $20 \%$ of the poorest obtain similar income level to the $20 \%$ of the richest. Economic results $\left(\mathrm{O}_{2}\right)$ are specified by the typical measure of production, i.e. GDP per capita. Resource productivity $\left(\mathrm{O}_{3}\right)$ is used to represent environmental gains, as it is higher when production processes use the smallest amount of resources, thus preventing degradation of the natural environment.

The data also specify the level of employment in four sectors: agriculture $\left(\mathrm{I}_{1}\right)$, industry $\left(I_{2}\right)$, market services $\left(I_{3}\right)$ and non-market services $\left(I_{4}\right)$ in 2015 . The agricultural sector is defined as encompassing economic activities within sections A-B of NACE Rev. 2; the industrial sector covers sections $\mathrm{C}-\mathrm{F}$; the market services are specified in sections $\mathrm{G}-\mathrm{N}$ and $\mathrm{R}-\mathrm{T}$; and the non-market services as sections $\mathrm{O}-\mathrm{Q}$ and $\mathrm{U}$. The levels of sectoral employment reflect the structural development of the countries under research, as employment shifts follow a universal pattern i.e. from agriculture to industry to the 
service sector. De-industrialisation is thus a trend typical of the most advanced economies, while high levels of employment in agriculture reveal an initial phase of development and may be symptoms of backwardness. The service sector is highly heterogeneous, and the relations between its market and non-market parts reflect institutional solutions adopted by each economy.

We assume that each kind of employment induces positive results for SD, as the alternative is specified by unemployment or economic inactivity. These phenomena are connected with both losses in economic yields, as well as social tensions. Moreover, labour inputs in a production process seem to be friendlier for the environment than technical equipment or natural resources usage.

Finally, in our model the countries were evaluated in terms of four inputs and three outputs:

$\mathrm{I}_{1}$ - employment in agriculture in thousand [from 15 to 64 years]/total population (2015)

$\mathrm{I}_{2}$ - employment in industry in thousand [from 15 to 64 years]/total population (2015)

$\mathrm{I}_{3}$-employment in market services in thousand [from 15 to 64 years]/total population (2015)

$\mathrm{I}_{4}$-employment in non-market services in thousand [from 15 to 64 years]/total population (2015)

$\mathrm{O}_{1}-1$ /income quintile share ratio [the ratio of total income received by the $20 \%$ of the population with the highest income to that received by the $20 \%$ of the population with the lowest income; equivalised disposable income] (2015)

$\mathrm{O}_{2}-$ GDP per capita [current prices, PPS per capita] (2015)

O3 - resource productivity [GDP/domestic material consumption (DMC)] (2015).

Detailed descriptive statistics of inputs and outputs are presented in Table 2.

The highest indicator of employment in agriculture is observed in Romania. The share is more than four times larger than the average. The agrarian character of Romanian economy reflects its low level of general development. Other countries with a high level of agricultural employment are Poland (53.2) and Greece (41.1). Conversely, the lowest employment in agriculture is found in Belgium. Slightly higher levels than Belgium are noted in the United Kingdom (UK) (6.7) and Germany (7.3). The researched countries are strongly diversified concerning the level of agricultural employment $(\mathrm{VC}=80 \%)$. Moreover, this is positively skewed (2.50) indicating that for the majority of countries the level of agricultural employment is lower than the average. Thus, there are only a few economies in the sample focusing their economic activity on the agrarian sector. This proves that most of the EU states have already transformed the traditional structure of employment.

An almost three times lower variation is observed when analysing employment in the industry. The Czech Republic is characterised by the highest level of industrial employment (176.2), followed by Slovakia (158.6) and Estonia (143.0). The lowest level is noted in Greece (48.4), the Netherlands (73.0) and Spain (75.4). Employment levels in the industry, like in agricultural employment, are lower than the average in the majority of countries.

The countries under study are least diversified concerning the level of employment in market services. The highest level is found in the UK (229.3) and the lowest in Romania (137.4). Moreover, the majority of countries is characterised by a market service employment indicator, which is higher than the average. Market-driven tertiarisation of the economy is thus typical for EU states.

Non-market service employment may be found mainly in Sweden (158.7) and Denmark (153.2), revealing strong connections with welfare state institutions. Conversely, Romania 


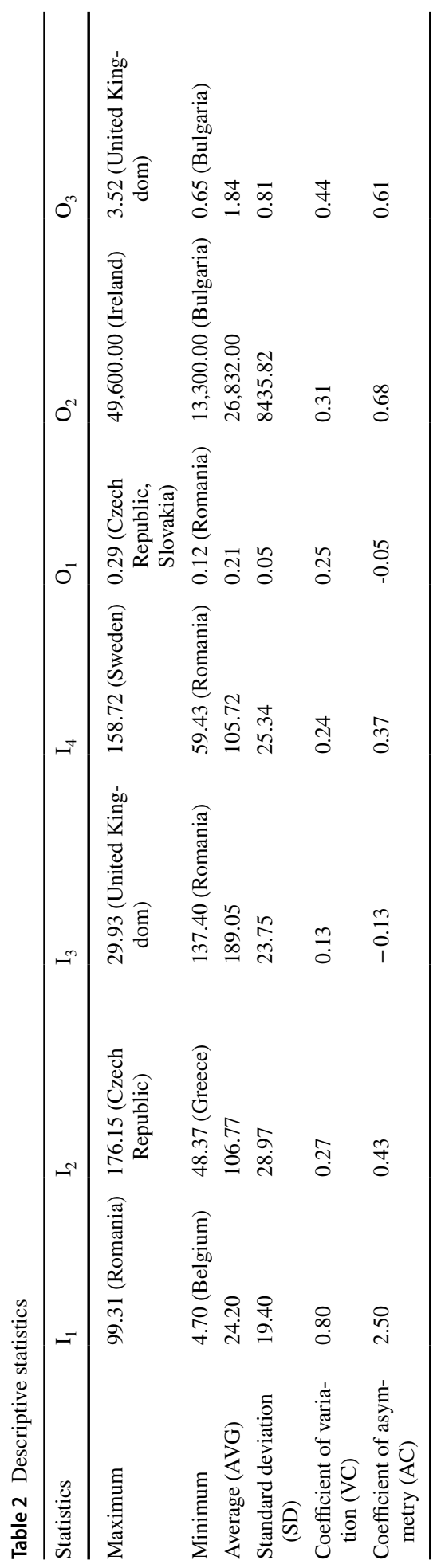


is the country where employment in non-market services is the lowest (59.4). Diversification between countries is at a medium level (24\%). Contrary to market services, the majority of countries exhibits lower levels of the indicators than the average. Thus, direct state interventionism is not a typical solution in EU countries.

Taking into account all outputs, the poorest results are observed twice in Bulgaria. The country has the lowest GDP per capita $\left(\mathrm{O}_{2}\right)$ as well as the lowest resource productivity $\left(\mathrm{O}_{3}\right)$. Weak results are also found in Romania, which is the country with the most unequal income distribution and second to last concerning levels of each of the previously mentioned variables.

Social problems stemming from income inequality seem to be the least serious in the Czech Republic and Slovakia. Institutional solutions connected with the historical experience of post-Soviet countries may partly explain such results. Concerning GDP per capita, the best results are attributed to Ireland, while slightly lower levels are found in the Netherlands, Austria, and Germany. The majority of EU countries is characterised by levels lower than the average. The poorest states are Bulgaria and Romania, followed by Croatia, Latvia, and Poland. The highest resource productivity is observed in the UK, and then in Italy and the Netherlands. Apart from Bulgaria, other raw material-intensive economies are Estonia, Latvia, and Finland, followed by Poland. The low efficiency of these economies is probably due to a relatively high level of coal energy usage which bases on traditional technologies.

Table 3 Canonical analysis results

\begin{tabular}{|c|c|c|c|}
\hline \multirow[t]{2}{*}{ Inputs } & \multicolumn{3}{|c|}{ Canonical variables } \\
\hline & $\mathrm{U}_{1}$ & $\mathrm{U}_{2}$ & $\mathrm{U}_{3}$ \\
\hline $\mathrm{I}_{1}$ & -0.589 & 0.222 & 1.231 \\
\hline $\mathrm{I}_{2}$ & 0.367 & 0.628 & 0.369 \\
\hline $\mathrm{I}_{3}$ & -0.727 & -0.640 & 0.608 \\
\hline $\mathrm{I}_{4}$ & 0.912 & 0.187 & 0.898 \\
\hline Canonical correlations & 0.805 & 0.761 & 0.554 \\
\hline Canonical $\mathrm{R}^{2}$ & 0.647 & 0.580 & 0.307 \\
\hline Chi square & 45.487 & 24.643 & 7.320 \\
\hline df & 12 & 6 & 2 \\
\hline Significance & 0.00001 & 0.00040 & 0.02575 \\
\hline Lambda Wilks & 0.103 & 0.292 & 0.694 \\
\hline Summary redundancy & & $56.348 \%$ & \\
\hline Redundancy indices & 0.275 & 0.238 & 0.050 \\
\hline \multirow[t]{2}{*}{ Outputs } & \multicolumn{3}{|c|}{ Canonical variables } \\
\hline & $\mathrm{V}_{1}$ & $\mathrm{~V}_{2}$ & $\mathrm{~V}_{3}$ \\
\hline $\mathrm{O}_{1}$ & 1.005 & 0.496 & -0.214 \\
\hline $\mathrm{O}_{2}$ & -0.054 & -0.836 & 1.016 \\
\hline $\mathrm{O}_{3}$ & 0.096 & -0.406 & -1.101 \\
\hline
\end{tabular}




\subsection{Canonical Correlations}

In order to assess the adequacy of input and output choices, we applied canonical analysis. Evaluation of the relationships between them is presented in Table 3.

The results allow us to conclude that state interventionism may strongly interfere with the distribution of income, as the correlation between employment in non-market services ratio $\left(\mathrm{I}_{4}\right)$ and inverse of income quintile share ratio $\left(\mathrm{O}_{1}\right)$ influenced the first (strongest) canonical correlation between inputs and outputs. The highest contribution to the second canonical variable had the following variables: $\mathrm{I}_{3}$-employment in market services ratio, and $\mathrm{O}_{2}-$ GDP per capita. Thus, the market services sector seems to have the strongest influence on economic results and appears to constitute a modern growth pole. In determining the third canonical variable, the greatest contribution was made by $\mathrm{I}_{1}$ and $\mathrm{O}_{3}$, i.e. employment in agriculture ratio and resource productivity ratio, suggesting that agricultural activity may be the most influential factor affecting a state's natural environment.

The total redundancy of all canonical variables shows that on a basis of inputs we can explain $56.3 \%$ of the variance of outputs. Since all p-values for correlations between each set of canonical variables are less than 0.05 , those sets reveal statistically significant relationships. This confirms the applicability of the model with four inputs and three outputs to assess sectoral employment efficiency.

\subsection{Selected Characteristics of Labour Markets}

To better understand a specificity of the economies under research, especially situation in their labour markets, it is useful to compare some basic characteristics of employment relationships. The general situation in a labour market can be recognised by tracking both unemployment rates and economic activity of population. Some relations between the maturity of economy, reflected by the general level of development, and such indicators may be found (Appendix 1, Table 6).

The most developed countries such as Sweden, Netherland, Denmark, Germany, the UK or Austria are characterised by the highest economic activity of population and limited tensions in a labour market as most of the people are able to find a job and a long-term unemployment is rarely suffered. Societies in these countries are also not facing severe problems with the inclusion of young people or women's employment.

The other group of countries, characterised by serious problems in a labour market, is constituted by economies of the South as well as the poorest post-socialist ones, namely Romania and Bulgaria. They experience not only problems with unemployment but also social tensions like low activity or problems with the exclusion of large groups, especially of the young.

Institutional and structural features of a labour market favour developmental gains. Some social benefits seem to stem from part-time employment solutions, which are most often found in the richest more inclusive economies. Nevertheless, temporary contracts, because of their dual character, may induce some chances for inclusion and some dangers of being put into social insecurity and a low wages trap. On the other hand, it may be favourable for well-educated professionals as well as for a general elasticity of a market. Thus, it may be difficult to specify direct relations between a level of development and a rate of temporary employment in the EU.

These phenomena are strongly connected not only with institutional solutions but with structural features of the economy as well (Appendix 1, Table 7). Sectoral composition 
of the economy, because of intersectoral differentiation in prevailing employment solutions and unique sectoral employment relations, strongly influence a general situation in a labour market. Generally, the industry is characterised by the most traditional employment relationships with full-time jobs created mainly for men. On the other hand, service sector, especially non-market services, is strongly feminised allowing for limiting gender disparities, at least specified by economic activity and employment. This pattern is repeated in most of the EU economies. Some exceptions are only found in Greece, Hungary, and Romania, where part-time employment is the least often adopted in non-market services. Such results are strongly influenced by a role of the state in delivering such services.

Labour market situation is nowadays more and more strongly influenced by migration processes. A flow of people is induced by many reasons, however, economic ones seem to be the most important. In this context factors stimulating the international flow of labour resources may be found in differences between unemployment rates and levels of remunerations between countries, as increased chances to improve the standard of living by well-paid job motivate to emigrate. Thus, a rate of net migration may be one of the indicators expressing situation in the economy, considering labour market conditions as well as institutional solutions and openness of society. Nevertheless, the position of immigrants in labour market is usually more difficult than natives, at least in the countries that attract an inflow of labour by a high level of development (Appendix 1, Table 6).

In the EU countries, the highest crude rates of net migration were observed in Germany and Austria followed by Sweden, Denmark, Belgium, and the UK. Thus, the most developed economies were the most attractive place to live for many foreigners. On the other hand, the outflow of people was found in the poorest member states such as Lithuania, Latvia, Croatia, Greece, Romania, Portugal, Bulgaria, Poland and Spain. The Baltic republics, the countries of the South and the poor new EU members are economies that either lose their human capital in favour of the more developed EU countries or constitute a short-time stop for migrants from African or Asian countries.

Moreover, the immigrants usually have difficulties with finding a job and this fact is expressed by a higher level of unemployment of immigrants than of total population. The strongest differences may be found in Spain, Greece, which are the countries with negative migration rate as their economic situation does not create favourable conditions for immigrant inclusion as well as in Finland, Belgium, which are the final destinations for immigrants although they suffer some internal problems in their labour markets. Thus, the unfavourable condition of economy limits chances of immigrant inclusion. On the other hand, Slovakia, Bulgaria, Poland, Hungary, and Lithuania are countries where immigrants usually find a job even easier than natives. Nevertheless, a dual character of such workplaces seems to be found, as immigrants are either highly specialised professionals or they do manual, temporary, and low-paid jobs found mainly in services, construction and agriculture.

\section{Non-radial CCR Model Results and Discussion}

\subsection{Three-Dimensional Efficiency}

The application of the NR-CCR model for comparing the efficiency of EU countries gives satisfactory results. The average efficiency exceeds $81 \%$, however, this indicates that nearly $20 \%$ of employment does not induce effects favourable to SD. Nevertheless, the situation 


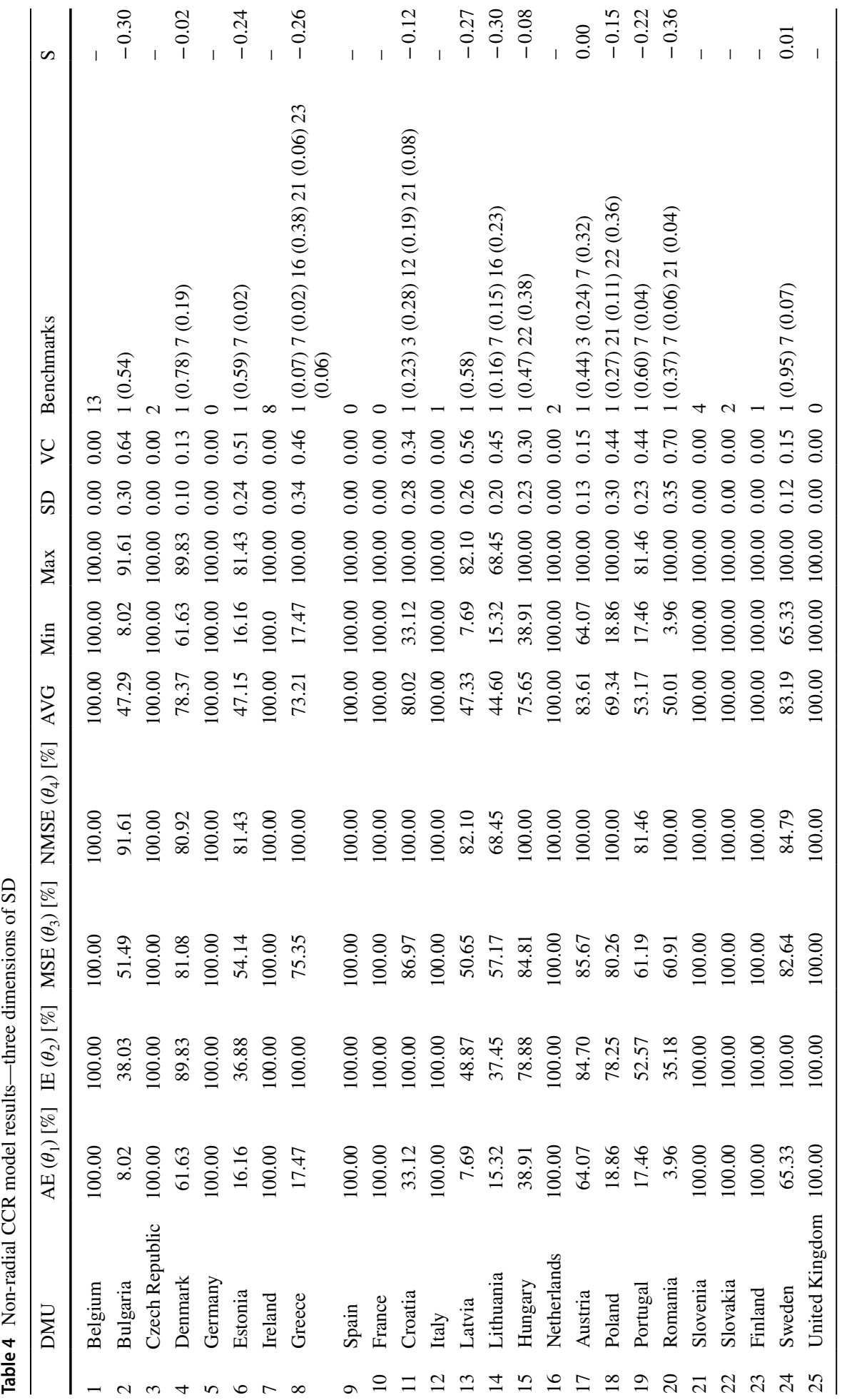




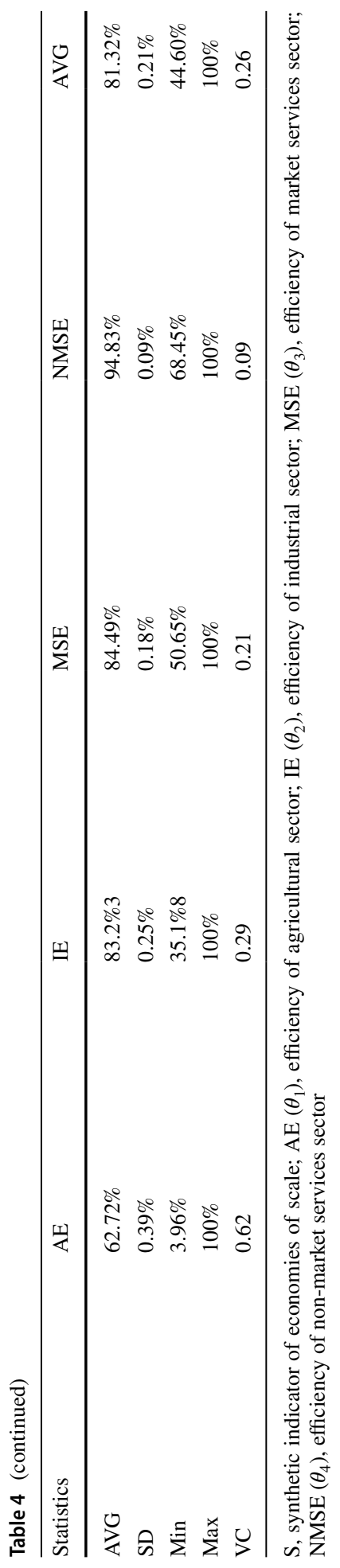


differs among economies. The research showed that there were 12 fully efficient countries (Table 4). The majority of them belong to the "old" EU members (Belgium, Germany, Ireland, Spain, France, Italy, the Netherlands, Finland and the UK). There were only 3 fully efficient countries in the "new" members group (accession in 2004 or later), e.g. the Czech Republic, Slovenia, and Slovakia. Conversely, the most serious challenges in transforming employment into SD were observed in the Baltic republics and the poorest economies. The poorest results were found in Lithuania (44.60\%), Estonia (47.15\%), Bulgaria (47.29) and Latvia (47.33\%). In these countries, more than half of employment does not have any effect in SD. Moreover, there were 11 economies with efficiency below average (81.32\%).

The countries under research were characterised by a moderate variation of the average efficiency at a level of $25.85 \%$. The specified efficiencies appeared to be far more diversified. The most diversified results were observed in agricultural employment $(62.19 \%)$, while the least in employment in non-market services $(9.44 \%)$. Moreover, the variation in industry efficiency was higher than that of market services $(29.46$ and $21.19 \%$ respectively). Thus, the reasons for the long-lasting developmental disparities among countries may be found in the rural structure of economies. The presence of the state in the economy in the form of non-market services employment usually reveals some equalising features.

The conclusion about the diversifying influence of employment in agriculture is additionally supported by the lowest average efficiency of this sector (62.72\%). Nearly $40 \%$ of rural employment does not induce effects favourable to SD, namely it does not increase the general GDP per capita level, does not equalise incomes in society and does not reduce environmental exploitation. Instead, it suggests that countries with rural employment are those with the most intense problems in harmonising developmental goals. Conversely, the best results are typical of employment in non-market services, where only about $5 \%$ of employment does not have an effect on SD. Thus, welfare state solutions can be found to be favourable for SD. The relationship between SD and employment in non-market services is mutual. Employment stimulates development, but at the same time, the most advanced economies with the highest and most equally distributed incomes and production processes that do not exploit the natural environment as they are organised according to the newest technological solutions, can afford to support welfare services, such as education or healthcare. The market-services and industry achieve similar results with only slightly lower efficiency than the former.

Thirteen economies presented inefficiencies in rural labour force engagement. Both "old" (5 countries) and "new" member states ( 8 countries) were among them. The lowest efficiency of agricultural employment was observed in Romania, where it reached $4 \%$. Low results were also noted in Latvia (7.69\%) and Bulgaria (8.02\%). These facts confirm the general conclusion that the biggest problems in SD appear in the poorest, transforming economies. From the group of "old" EU members, mainly Greece and Portugal presented inefficient agricultural employment. The situation in these economies could be influenced by the latest socio-economic crisis; however, long-term structural features involving the high share of agriculture in these economies could be among the most important reasons. The same countries-the poorest and the Baltic republics-were characterised by the strongest inefficiencies also in industry and market services. Moreover, only 7 countries were inefficient in terms of employment in non-market services. This fact confirms that the non-market service sector is the most favourable to SD. Economies with inefficiencies were ranked as follows (in descending order of inefficiency): Bulgaria (91.61\%), Sweden (84.79\%), Latvia (82.10\%), Portugal (81.46\%), Estonia (81.43\%), Denmark (80.92\%) and Lithuania (68.45\%). 
Economies, which are fully efficient in terms of all inputs, could constitute the benchmark for the rest of the 13 countries. The role was attributed most often to Belgium (13 times), Ireland (8 times) and Slovenia (4 times). Moreover, Belgium was the only benchmark for Bulgaria and Latvia, which suggests that Belgium's pattern of structural development could be adopted by these catching-up economies. Germany, Spain, France and the UK, although fully efficient, did not adopt the role of the benchmark, revealing some unique structural relationships difficult to be followed by any other country.

The majority of inefficient countries (with the exception of Sweden and Austria) revealed diseconomies of a small scale (see synthetic indicator $S$ in Table 4). This proves that the higher the level of employment per capita is, the best result in the SD process can be achieved. Nevertheless, the example of Sweden (with diseconomies of a large scale) shows that a high rate of employment may also lead to some problems, especially in the environmental dimension of SD. The Austria case (with a constant-scale economy) suggests that inefficiency in the process of SD may be connected with some other features of the economy not specified by employment level. Considering the levels of diseconomies, it is worth noting that the strongest small-scale inefficiencies were observed in Romania, Bulgaria, and Lithuania, thus in economies with serious problems in the labour market. An increase in employment level, specified mainly by a decrease in unemployment, could positively influence efficiency towards the pursuit of integrated development.

Differences in the detailed efficiencies for the specified inputs suggest that there is a possibility of substitution of inputs to achieve an optimal solution. The indicators of labour inputs substitution between sectors, as well as synthetic indicators ( $z$ ) for the 25 EU countries, are presented in Table 5.

Substitution indicators suggest some sectoral directions of a shift in employment favourable to SD. The strongest labour movement should take place from the agricultural sector into the non-market services sector. This should be supported by a de-agrarian trend in favour of market services and the industry. Moreover, some moderate shifts from the industry and from market services to non-market services are required. The general scale of substitution between labour inputs in the EU countries reaches $25 \%$.

The strongest structural changes are required in Romania. The most important shift in labour concerns the move from agriculture into non-market and market services. The agrarian structure of the economy is thus found as the strongest barrier to its SD. In order to achieve the optimal solution in pursuit of $\mathrm{SD}$, a strong substitution between inputs is also required in Bulgaria and Latvia. The directions of the shift are similar to those specified for Romania. It is necessary to limit employment in agriculture, as it is inefficient, in favour of more efficient sectors. In both cases, these are non-market services, market services, and the industry. Other countries with a great need of inputs substitution include postsocialist countries, such as Estonia, Poland, and Lithuania. The results stress the fact that in transforming, catching-up economies, patterns of employment should change in order to achieve success in SD.

Summing up, regardless of the level of development there is an urgent need for the deagrarisation of employment to improve results in SD processes. Over-employment in this sector limits economic, social and environmental gains from labour engagement in the economic activity. Nevertheless, problems with inefficient employment in terms of the aims of integrated development are most pronounced in "new" EU member states.

In order to compare results from each sector of employment for different dimensions of SD efficiency, we analysed separately the social, economic and environmental spheres in the next sections. 
Table 5 Detailed indicators of labour inputs substitution between sectors and a synthetic indicator of substitution $(z)$

\begin{tabular}{|c|c|c|c|c|c|c|c|}
\hline DMU & $\mathrm{A} / \mathrm{I}$ & $\mathrm{A} / \mathrm{MS}$ & A/NMS & $\mathrm{I} / \mathrm{MS}$ & I/NMS & MS/NMS & $\mathrm{z}$ \\
\hline Belgium & 1.00 & 1.00 & 1.00 & 1.00 & 1.00 & 1.00 & 1.00 \\
\hline Bulgaria & 0.21 & 0.16 & 0.09 & 0.74 & 0.42 & 0.56 & 3.55 \\
\hline Czech Republic & 1.00 & 1.00 & 1.00 & 1.00 & 1.00 & 1.00 & 1.00 \\
\hline Denmark & 0.69 & 0.76 & 0.76 & 1.11 & 1.11 & 1.00 & 1.21 \\
\hline Germany & 1.00 & 1.00 & 1.00 & 1.00 & 1.00 & 1.00 & 1.00 \\
\hline Estonia & 0.44 & 0.30 & 0.20 & 0.68 & 0.45 & 0.66 & 2.39 \\
\hline Ireland & 1.00 & 1.00 & 1.00 & 1.00 & 1.00 & 1.00 & 1.00 \\
\hline Greece & 0.17 & 0.23 & 0.17 & 1.33 & 1.00 & 0.75 & 2.20 \\
\hline Spain & 1.00 & 1.00 & 1.00 & 1.00 & 1.00 & 1.00 & 1.00 \\
\hline France & 1.00 & 1.00 & 1.00 & 1.00 & 1.00 & 1.00 & 1.00 \\
\hline Croatia & 0.33 & 0.38 & 0.33 & 1.15 & 1.00 & 0.87 & 1.64 \\
\hline Italy & 1.00 & 1.00 & 1.00 & 1.00 & 1.00 & 1.00 & 1.00 \\
\hline Latvia & 0.16 & 0.15 & 0.09 & 0.96 & 0.60 & 0.62 & 3.29 \\
\hline Lithuania & 0.41 & 0.27 & 0.22 & 0.66 & 0.55 & 0.84 & 2.27 \\
\hline Hungary & 0.49 & 0.46 & 0.39 & 0.93 & 0.79 & 0.85 & 1.62 \\
\hline Netherlands & 1.00 & 1.00 & 1.00 & 1.00 & 1.00 & 1.00 & 1.00 \\
\hline Austria & 0.76 & 0.75 & 0.64 & 0.99 & 0.85 & 0.86 & 1.25 \\
\hline Poland & 0.24 & 0.23 & 0.19 & 0.97 & 0.78 & 0.80 & 2.31 \\
\hline Portugal & 0.33 & 0.29 & 0.21 & 0.86 & 0.65 & 0.75 & 2.22 \\
\hline Romania & 0.11 & 0.07 & 0.04 & 0.58 & 0.35 & 0.61 & 5.51 \\
\hline Slovenia & 1.00 & 1.00 & 1.00 & 1.00 & 1.00 & 1.00 & 1.00 \\
\hline Slovakia & 1.00 & 1.00 & 1.00 & 1.00 & 1.00 & 1.00 & 1.00 \\
\hline Finland & 1.00 & 1.00 & 1.00 & 1.00 & 1.00 & 1.00 & 1.00 \\
\hline Sweden & 0.65 & 0.79 & 0.77 & 1.21 & 1.18 & 0.97 & 1.24 \\
\hline United Kingdom & 1.00 & 1.00 & 1.00 & 1.00 & 1.00 & 1.00 & 1.00 \\
\hline EU-25 ${ }^{\mathrm{a}}$ & 0.75 & 0.74 & 0.66 & 1.33 & 0.88 & 0.89 & 1.25 \\
\hline
\end{tabular}

A, agricultural sector; I, industrial sector; MS, market services sector; NMS, non-market services sector

${ }^{a}$ Indicators of substitution calculated basing on the average for the 25EU efficiency indicators of employment in the four sectors

\subsection{Social Efficiency}

Generally, the results of the assessment of the social efficiency of employment in the 25 EU countries were relatively favourable to SD. Social efficiency was, on average, almost $72 \%$, which means a relatively positive employment impact on the achievement of cohesion as reflected by equal income distribution in society (Appendix 2, Table 8).

Among benchmarks were countries such as Belgium (18 times), the Netherlands (once), Finland (once), Slovenia, the Czech Republic (twice) and Slovakia (3 times). This means that those countries had the most egalitarian income distribution system resulting in sustainable social relationships through the employment channel. Employment in these countries allowed for minimising disproportion between the poorest and the richest. Thus, 
employment can be considered as a driving factor for inclusion, as well as for the reduction of social tensions caused by material status.

The lowest level of social efficiency was found in Lithuania, where it was slightly below $40 \%$. Low efficiency was also observed in the rest of the Baltic states, i.e. Estonia and Latvia, as well as in the poorest member countries, i.e. Romania and Bulgaria. In these economies, social efficiency was below $50 \%$ of the optimum. Thus, the largest social disparities in income distribution were observed in the catching-up economies. In these countries, employment often leads to income polarisation-generating high incomes for some social groups and low for others. The dual nature of employment can, therefore, be a significant threat to SD of these countries.

Almost all inefficient countries were characterised by disadvantages of a small scale. The only exception was Sweden, where a size of the economy does not generate inefficiencies. Generally, more favourable social effects were obtained by states with essential employment scale, i.e. where higher rates of economic activity and lower unemployment rates were observed.

By comparing the social efficiency of employment in various economic sectors we can draw some general conclusions. The highest level of social employment was observed in the non-market services sector (91\%). Thus, it should be recognised that services, predominantly related to the implementation of welfare state functions, affected the minimisation of income disparities in societies. The industrial and market services sectors achieved a lower level of efficiency, about $1 / 4$ lower than the optimal value (78\% and $74 \%$ respectively). The lowest social efficiency was observed in the agricultural sector, with an average of only $44 \%$ and strong differentiation. Thus, economies with an agrarian employment structure were likely to experience the greatest social tensions induced by income disparities.

It must be stressed that, from a social point of view, employment in agriculture was the least favourable, while the most favourable was in non-market services. Therefore, increasing the efficiency of employment requires mostly a shift of labour resources from the agricultural sector to the non-market services sector. Patterns of efficiency improvement for individual economies, however, might differ from this general scheme taking into account some specific national conditions.

Indicators of substitution for the $25 \mathrm{EU}$ members (Appendix 2, Table 9) prove that the most desirable is the employment shift from agriculture to non-market services, and then from agriculture to the industry as well as to market services. In addition, it would be favourable to increase employment in non-market services at the expense of market services, as well as of the industry. From the point of view of equal income distribution, a shift of employment from market services to the industry would be also required; however, the level of such a shift is rather small (5\%). The overall scale of substitution of employment across sectors is significant and stands at $45 \%$. Bulgaria, Lithuania, and Latvia are the economies where the largest cross-sectoral shifts are desired.

\subsection{Economic Efficiency}

Comparisons of the economic efficiency of employment in the four sectors among the 25 EU countries support additional interesting results (Appendix 2, Table 10). The average level of economic efficiency for the analysed economies is moderate and reaches about $59 \%$ of the full efficiency. Efficiency exceeding the average was observed in 12 economies 
(among others, in 4 benchmarks) and it was a characteristic observed only in the "old" member states. Only two "old" member states, i.e. Greece and Portugal, were placed below the average, nevertheless, these economies gained relatively high results within the group of inefficient countries.

Considering efficiency in the economic dimension it is possible to specify 4 benchmarks: Belgium, Germany, Ireland and the Netherlands. Employment in these economies in all sectors is fully efficient and allows the optimisation of GDP per capita. Conversely, the lowest efficiency, at about $1 / 4$ of the full efficiency, is found in Bulgaria. Unfavourable results in the economic dimension are also noted in Latvia, Romania, Croatia, Lithuania and Poland. Generally, some positive relations between economic efficiency and maturity of the market economy, as well as the duration of EU membership may be specified. The "new" member states that have accessed the EU not earlier than 2004 are characterised by essentially lower efficiency. A group of benchmarks includes only the "old" economies and relatively moderate efficiency losses are found in the rest of the "old" member states.

Comparisons of the intensity of scale effects indicator $(S)$ between the specified economies prove that diseconomies of a small scale are observed for the majority of inefficient countries. Thus, more favourable economic results are typical of a higher scale of employment. The only exception is Sweden, where moderate diseconomies of a large scale are noted. These properties suggest that structural relations resulting in economic inefficiencies are influenced by a minimal scale of employment, unemployment and economic inactivity.

Essential information may be deduced when comparing the economic efficiency of each sector. This points at different results from human resources engagement and constitutes a base upon which to specify optimal schemes of intersectoral substitution that explain directions of labour shifts favourable for an increase in GDP per capita. Average efficiency appears to be the lowest when considering employment in the industry. Low efficiency is also attributed to agricultural employment. Relatively high economic efficiency is found when assessing employment in market services and even higher in non-market services.

Comparisons of the economic efficiency of each sector suggest that in order to increase production levels, it is necessary to make a structural shift of employment into the service sector. This conclusion is in line with the three-sectoral theory of development. Nevertheless, the detailed patterns of substitution are diversified among countries (Appendix 2, Table 11).

The substitution indicators calculated based on the average for the 25 EU indicators of the economic efficiency of employment in different sectors suggest the necessary directions of structural changes. The strongest shifts are needed from the industry into non-market and market services. Moreover, it would be favourable to increase employment in non-market services at the expense of agriculture. Those employed in agriculture should move into market services as well. Nevertheless, employment in agriculture appears to be more favourable than in the industry. The level of substitution between market and non-market services is minimal. The aggregate level of employment substitution reaches $13 \%$. The most pronounced structural changes favourable for economic efficiency are necessary in Romania. 


\subsection{Environmental Efficiency}

The 25 EU countries have scored very low regarding their average level of environmental efficiency of employment (only $50 \%$ of the optimal). Thus, about half of employment does not influence the productivity of resource usage that could stimulate environmental preservation (Appendix 2, Table 12). Of the entire group of countries, only 9 achieve environmental efficiency above average and among these only 4 are fully efficient. The benchmark is Spain, Italy, the Netherlands and the UK.

The poorest results were observed in Bulgaria, Estonia, Romania, and Latvia. In order to achieve the observed resources productivity, it would be enough to employ not more than $20 \%$ of those currently employed. Moreover, slightly more than $1 / 4$ of employment would be enough to achieve the observed resources productivity in Finland and Poland.

It must be stressed that all environmentally inefficient economies are specified by the inefficiency of a small scale. Thus, the increase in employment could proportionally increase the productivity of material resources usage.

Structural relations play an essential role in the creation of solutions favourable for high resources productivity. Pro-environmental schemes of employment are different in each sector, and their identification should form a base upon which to formulate advice for developmental policy. The market services sector is characterised by the highest level of environmental efficiency. The average efficiency achieved was 57\%. Environmental efficiency in the industry was also higher than the average at around $52 \%$. The non-market services sector achieved efficiency of a little below 50\%. Agriculture achieved the lowest environmental efficiency of employment (below 42\%). Different results for each sector concerning the environmental efficiency of employment draw attention to the desirable direction of labour inputs substitution (Appendix 2, Table 13).

Considering the average levels of environmental efficiency for each sector, it is possible to specify both the scale and directions of structural shifts in employment favourable to environmental preservation. The synthetic indicator of substitution shows that the scale should cover about $18 \%$ of employment. The strongest movement from agriculture into market services, followed by a shift into the industry and finally into non-market services. A little lower substitution is expected into market services from non-market services. Substitution scale at only $9 \%$ concerns labour reallocation from industry into market services. The smallest change that optimizes the productivity of resources is specified by a shift from industry into non-market services. The most serious structural changes are necessary in Romania.

\section{Conclusions}

$\mathrm{SD}$, which seeks to harmonise social, economic and environmental capital, has become a reference point for rational policies, including policies on the allocation of labour resources. The task of improving the efficiency of resource allocation requires, firstly, the identification of the current state, secondly the diagnosis of the required shifts in employment, and finally the implementation of the suggested changes. The presented results may support the two first elements by providing general conclusions about the economic, social and environmental efficiency of EU employment, as well as suggestions for a shift in employment. It is worth stressing that even though there are some 
scientific analyses focused on the economic results of structural changes in employment, this paper concerns some neglected areas of compound SD goals. It is focused on specifying sectoral employment relation to multidimensional development and thus goes further than typical studies of aggregate productivity and growth.

Conclusions may be drawn regarding three areas:

- suggestions based on the inter-sectoral comparisons of efficiency, which may allow for the indication of structures of employment that are most favourable to SD, thus fulfilling the main aim of this paper;

- remarks influenced by the comparison of the three dimensions of SD, identifying the most essential problems that require special attention in developmental policy;

- conclusions based on cross-country comparisons, which will help us to specify the most efficient economies and verify our initial hypothesis that better results are observed in the "old" EU member states than in the "new" ones.

Considering the first area, the main findings prove that a universal pattern of structural changes specified in the three-sectoral theory is favourable to SD in the EU. It was made clear that efficiency of employment is at its highest in the service sector and at its lowest in agriculture. This conclusion holds true for the compound process of SD; however, some special features describe each dimension. While employment in non-market services is found to be the most favourable to economy and society, market services are the best for the environment. Agricultural employment is the least efficient considering social and environmental gains, but it is outplaced by industry in the economic dimension. Nevertheless, the paper sheds light on some arguments in a discussion about de- and reindustrialisation. The detailed indices may differ concerning the set of aims adopted by policymakers, however, in all cases, growing share of service employment is both an inevitable objective trend and a signal of maturity of economy developing into sustainability. Thus, a structural policy cannot neglect servicisation process and it should rather direct it into a more inclusive, clean and knowledge-intensive one instead of set limitations with industrialisation slogans.

Comparisons among the three dimensions of development lead to the conclusion that the sphere that requires the most attention is the environmental one. It was shown to have the lowest efficiency and highest variability among the countries examined, especially between the "old" and "new" EU member states. Considering the strong external effects of the environmental sphere, differentiation leads to a decrease in the general living standards across the EU. Thus, common efforts are especially required to protect the natural environment.

Conversely, the highest level of employment efficiency was observed in the social sphere, where the examined 25 EU countries were also the least varied. This supports the general statement that employment, as an alternative to inactivity and unemployment, is favourable for social goals and may constitute the main instrument in social policy. The fact sets a huge challenge for an educational system, which must be able to prepare young people to successfully enter a labour market as well as for policy aimed at increasing the inclusivity of economy, especially in a face of growing flow of migrants. Moreover, additional challenge is specified by a necessity to increase sectoral mobility of workers, that is especially important for elderly employees.

Even though a high level of employment may induce gains in all dimensions of SD, the structural allocation of labour may differ in its importance. The results of this research 
suggest that large adjustments in the structure of employment are required in order to improve social efficiency, followed by environmental and economic efficiency. At first glance, this observation seems to be at odds with the observation that the highest employment efficiency is observed in the social sphere. As a high level of employment is generally better for the equal distribution of income, resulting in high efficiency, it is possible to improve it by adjusting the structure of employment. The fact once again stresses a necessity of de-agrarisation of employment and of a growth of welfare services. Additionally, the environmental efficiency of employment is low and it is difficult to improve it by making structural shifts. It proves strong externalities connected with environmental issues in any sector and allows for suggestion for wide horizontal rules in its protection.

Considering the third area of findings it is possible to point out a strong divide between the two groups of EU member states - the "old" and the "new" ones. The obtained results confirmed that the employment shift towards structures created in the highly developed EU countries may contribute to the improvement of employment efficiency across the EU. The highly developed countries were characterised by a relatively low level of employment in agriculture and achieved higher efficiency. A relatively low level of efficiency, in particular of the "new" EU member states, suggested a need for further reallocation of the labour force, i.e. the employment shift from less efficient sectors, primarily agriculture, to market and non-market services. This observation positively verifies the research hypothesis about a higher level of SD in structurally more mature economies. It also justifies the need for cohesion policy in the EU that supports the least developed countries as all dimensions of SD have some external effects for the whole European community.

The countries of the former Eastern Bloc are most in need of making employment shifts. In this group, Romania, Bulgaria, and the Baltic republics experience the strongest losses in efficiency. Apart from a low level of employment efficiency, the "new" countries face other problems, such as social stratification, income inequalities, low economic activity and early abandonment of the labour market. A significant share of the workforce in these countries was or is employed in the least productive sector, i.e. in agriculture. Their limited mobility, relatively poor health, lack of competencies required in a diversified labour market, or common reluctance to change jobs are great constraints in the flow of human resources. The solution to this situation, which facilitates the free movement of labour resources from low to highly efficient sectors, is to increase the knowledge, skills, and competencies of people working in the primary sectors. Thus, it seems to be necessary to cover such groups of people by a lifelong learning programs that are focused on increasing their intersectoral mobility. Moreover, it becomes more and more important to modernise a system of education to prepare young people for challenges of a knowledge-based service economy. Another political issue in this "new" member states is specified by a migration issue, which, in opposition to problems with a massive inflow of refugees to the West and North EU countries, is specified by net outflow of human resources and a "brain drain" problem. In a long-term it may be limited only by enhancing general efficiency and levering development and this requires rational structural policy. It is necessary to create such workplaces that are able to engage especially the young people with high ambitions, who are often university graduates and are just starting their professional career. Such jobs can be found mainly in the knowledge-intensive services.

Another problem in the majority of Central and Eastern European countries is the high level of environmental pollution caused by the use of energy-intensive technologies of production and the excessive greenhouse gas emissions associated primarily with the use of 
hard coal as a primary source of energy. This pollution is generated mainly in economies with a substantial share of agricultural employment. Suggested changes in the employment structure of these economies, relying on the concentration of labour resources in high-tech, knowledge-intensive sectors would not only contribute to an increase in efficiency but would significantly reduce pressure on the environment.

The research findings show that there exist benchmark economies that perform in the most efficient way while transforming employment into SD. Although each economy may adopt some unique pattern of development, "old" EU member states, such as Belgium, the Netherlands or Ireland, most often constitute the benchmarks for the catching-up economies. A high level of service employment and a de-agrarian trend are typical features of high-performing states. Moreover, the role of non-market services in these economies cannot be over-appreciated, pointing at the importance of welfare state solutions.

Summing up, this study may be useful to governmental institutions of individual EU countries in terms of their employment policy. Suggested changes in the employment structure can be used by decision-makers to improve employment efficiency. Research results may be useful not only for decision-makers from the EU countries, but also for those from the EU candidate countries, which already before the accession or when preparing for it (e.g. the Balkan states, Ukraine or Turkey) can make a diagnosis and analysis of employment efficiency and on this basis, develop strategies how to increase it.

The research method proposed in the paper can also be used in the diagnosis of the efficiency of areas such as environmental protection, education, healthcare or efficiency of privatisation and restructuring processes. Finally, the use of DEA provides a methodological linkage among economic, environmental and social areas of SD, so enhancing the practicality in mitigating their problems. This study provides guidelines for future research works on DEA on economic, social and environment issues. The sectoral results may still not be enough to formulate suggestions toward implementing reforms that lead to SD and the branch or even enterprise level may help to provide better guidance.

Acknowledgements The authors thank professor Artur Prędki, and two anonymous reviewers for their helpful comments and suggestions to this study.

Funding This study was supported by the Ministry of Science and Higher Education (MNiSW) in Poland, Grant Number 8838/E-546/S/2017.

\section{Compliance with Ethical Standards}

Conflict of interest The authors declare that they have no conflict of interest.

Open Access This article is distributed under the terms of the Creative Commons Attribution 4.0 International License (http://creativecommons.org/licenses/by/4.0/), which permits unrestricted use, distribution, and reproduction in any medium, provided you give appropriate credit to the original author(s) and the source, provide a link to the Creative Commons license, and indicate if changes were made.

\section{Appendix 1}

See Tables 6 and 7. 


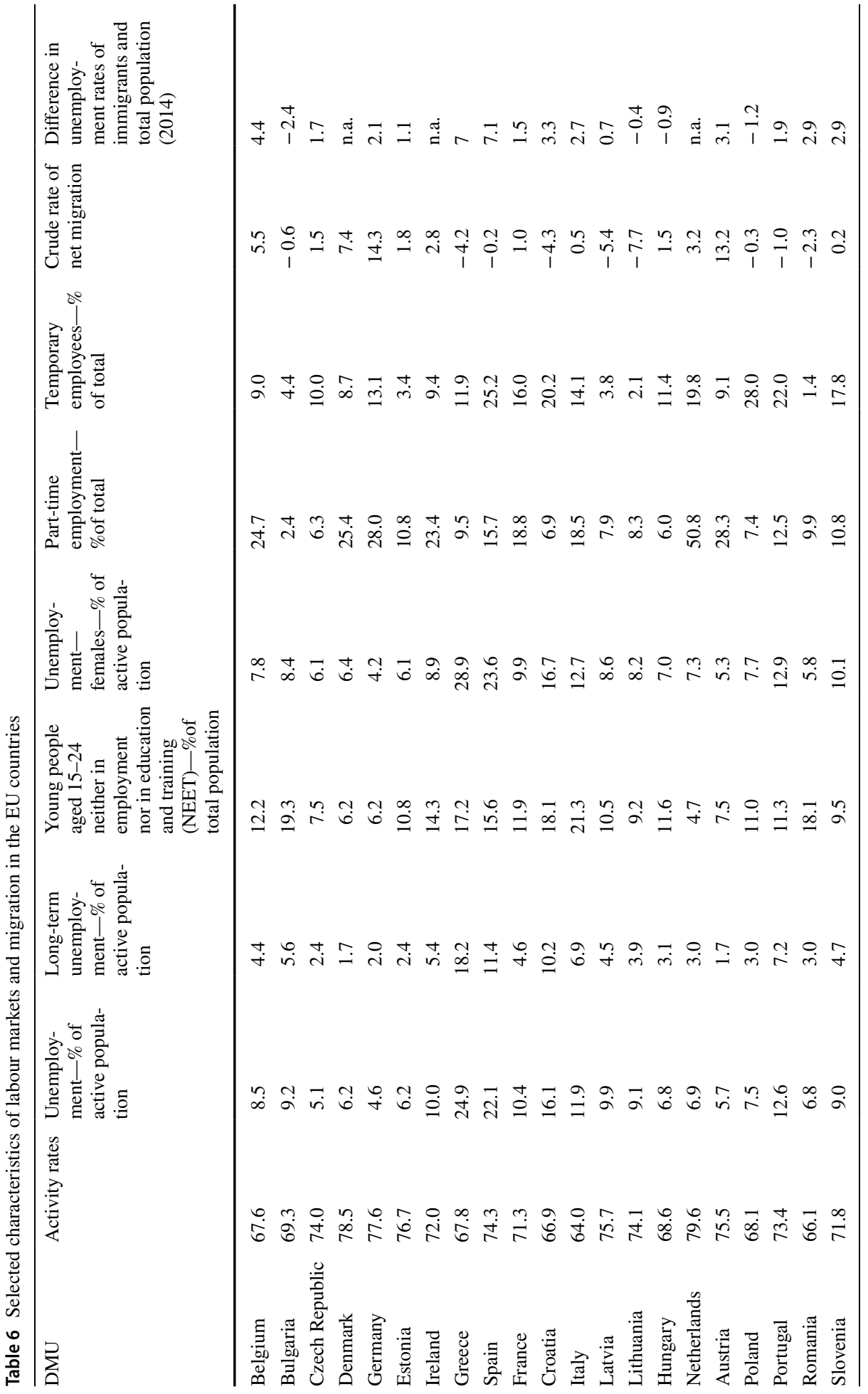




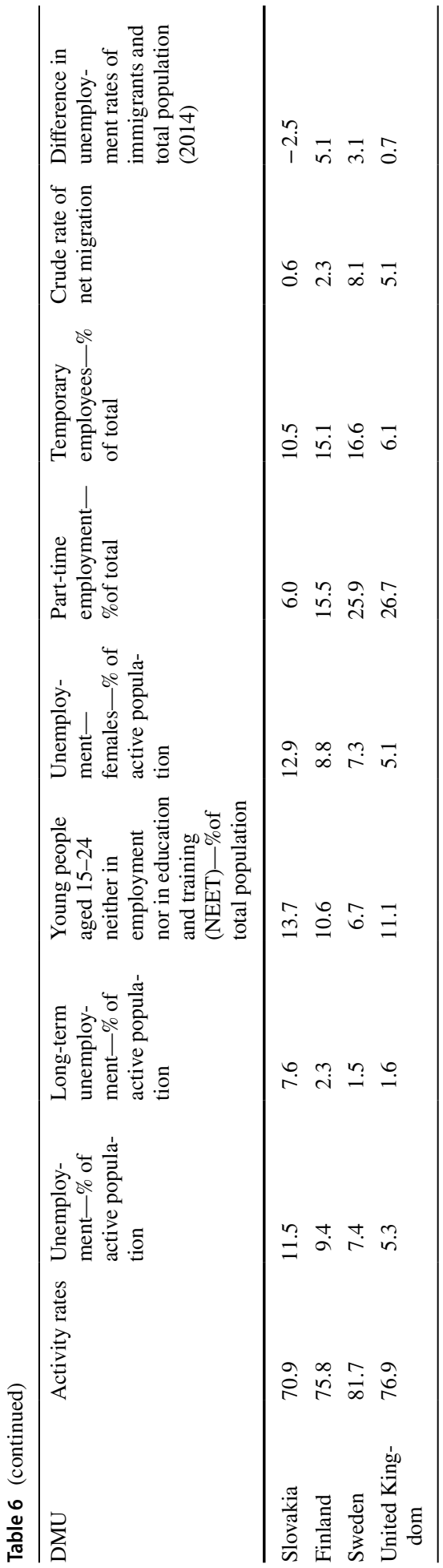

글 Springer 


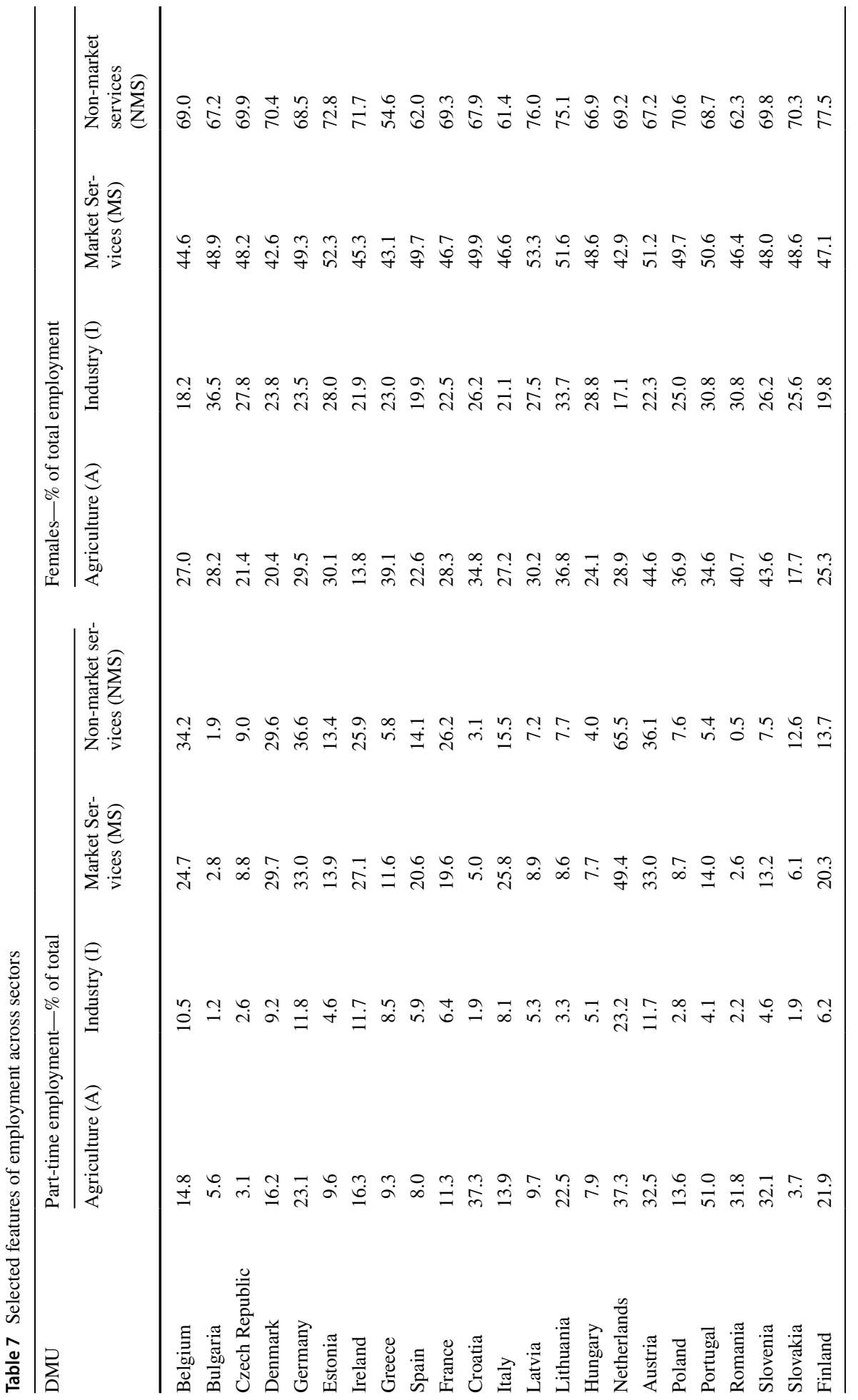




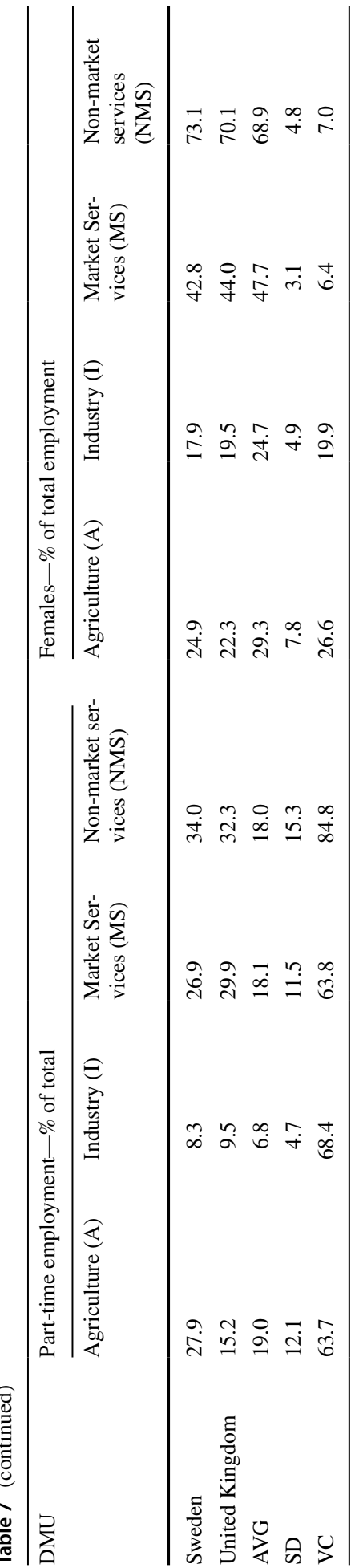




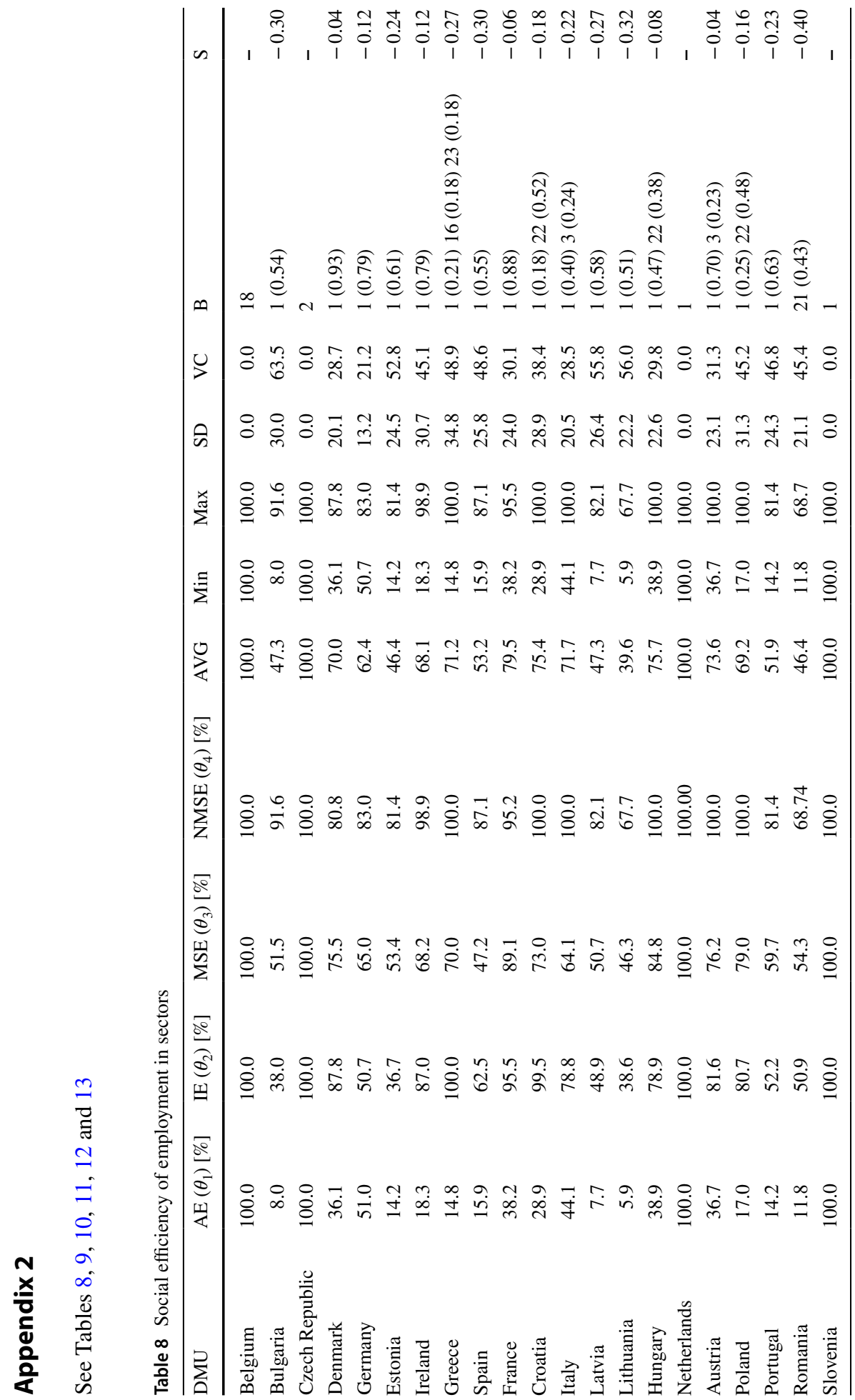




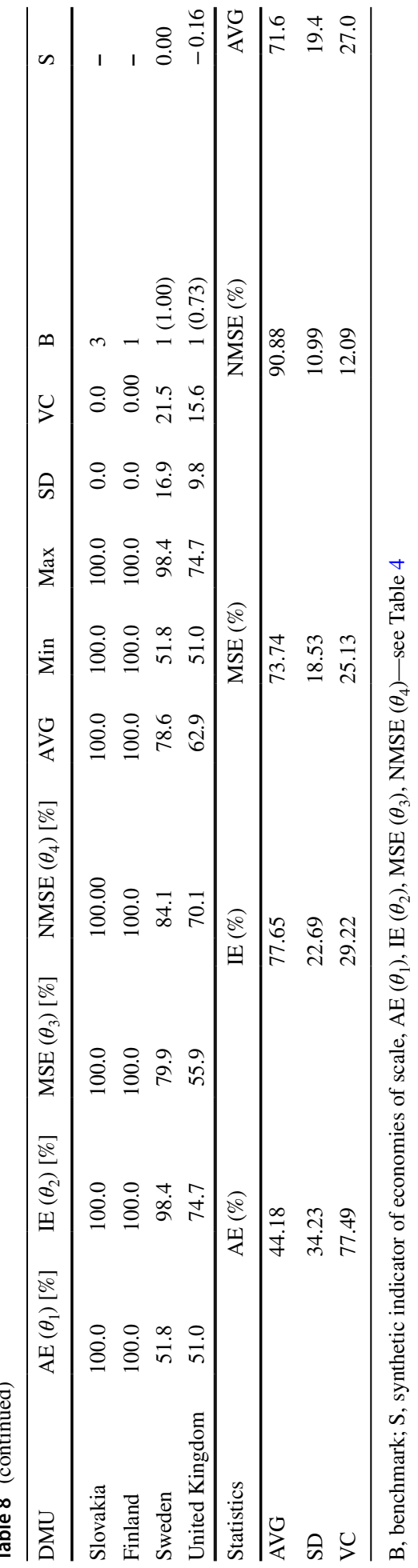

型 Springer 
Table 9 Detailed indicators of labour inputs substitution between sectors and a synthetic indicator of substitution $(\mathrm{z})$ - social efficiency optimization

\begin{tabular}{llllllll}
\hline DMU & A/I & A/MS & A/NMS & I/MS & I/NMS & MS/NMS & z \\
\hline Belgium & 1 & 1 & 1 & 1 & 1 & 1 & 1 \\
Bulgaria & 0.21 & 0.16 & 0.09 & 0.74 & 0.42 & 0.56 & 3.55 \\
Czech Republic & 1 & 1 & 1 & 1 & 1 & 1 & 1 \\
Denmark & 0.41 & 0.48 & 0.45 & 1.16 & 1.09 & 0.93 & 1.58 \\
Germany & 1.01 & 0.78 & 0.61 & 0.78 & 0.61 & 0.78 & 1.33 \\
Estonia & 0.39 & 0.27 & 0.17 & 0.69 & 0.45 & 0.66 & 2.55 \\
Ireland & 0.21 & 0.27 & 0.19 & 1.28 & 0.88 & 0.69 & 2.42 \\
Greece & 0.15 & 0.21 & 0.15 & 1.43 & 1.00 & 0.70 & 2.39 \\
Spain & 0.25 & 0.34 & 0.18 & 1.33 & 0.72 & 0.54 & 2.46 \\
France & 0.40 & 0.43 & 0.40 & 1.07 & 1.00 & 0.94 & 1.49 \\
Croatia & 0.29 & 0.40 & 0.29 & 1.36 & 0.99 & 0.73 & 1.96 \\
Italy & 0.56 & 0.69 & 0.44 & 1.23 & 0.79 & 0.64 & 1.56 \\
Latvia & 0.16 & 0.15 & 0.09 & 0.96 & 0.60 & 0.62 & 3.29 \\
Lithuania & 0.15 & 0.13 & 0.09 & 0.83 & 0.57 & 0.68 & 3.50 \\
Hungary & 0.49 & 0.46 & 0.39 & 0.93 & 0.79 & 0.85 & 1.62 \\
Netherlands & 1 & 1 & 1 & 1 & 1 & 1 & 1 \\
Austria & 0.45 & 0.48 & 0.37 & 1.07 & 0.82 & 0.76 & 1.67 \\
Poland & 0.21 & 0.21 & 0.17 & 1.02 & 0.81 & 0.79 & 2.44 \\
Portugal & 0.27 & 0.24 & 0.17 & 0.87 & 0.64 & 0.73 & 2.45 \\
Romania & 0.23 & 0.22 & 0.17 & 0.94 & 0.74 & 0.79 & 2.44 \\
Slovenia & 1 & 1 & 1 & 1 & 1 & 1 & 1 \\
Slovakia & 1 & 1 & 1 & 1 & 1 & 1 & 1 \\
Finland & 1 & 1 & 1 & 1 & 1 & 1 & 1 \\
Sweden & 0.53 & 0.65 & 0.62 & 1.23 & 1.17 & 0.95 & 1.39 \\
United Kingdom & 0.68 & 0.91 & 0.73 & 1.34 & 1.06 & 0.80 & 1.26 \\
EU-25 & 0.57 & 0.60 & 0.49 & 1.05 & 0.85 & 0.81 & 1.45 \\
\hline
\end{tabular}

${ }^{a}$ Indicators of substitution calculated basing on the average for the 25EU social efficiency indicators of employment in the four sectors 


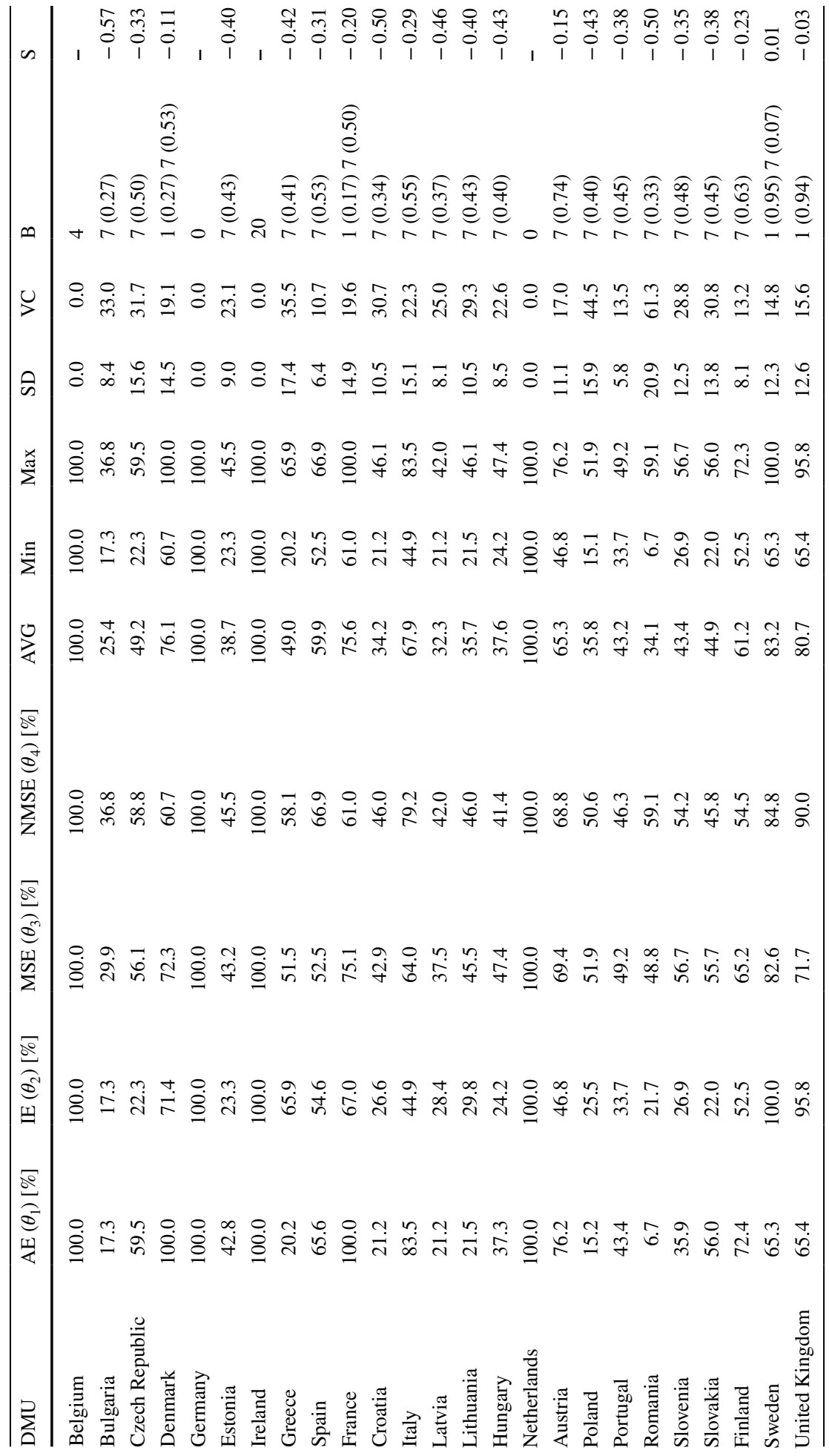




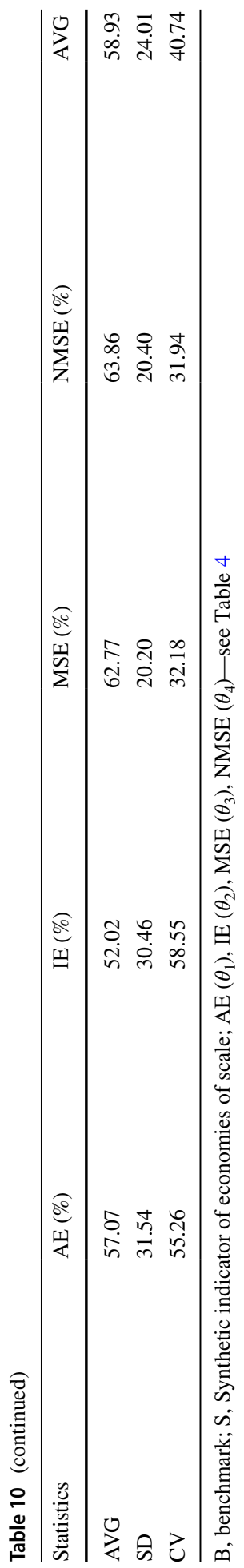


Table 11 Detailed indicators of labour inputs substitution between sectors and a synthetic indicator of substitution (z)—economic efficiency optimization

\begin{tabular}{|c|c|c|c|c|c|c|c|}
\hline DMU & $\mathrm{A} / \mathrm{I}$ & $\mathrm{A} / \mathrm{MS}$ & A/NMS & $\mathrm{I} / \mathrm{MS}$ & I/NMS & MS/NMS & $\mathrm{z}$ \\
\hline Belgium & 1 & 1 & 1 & 1 & 1 & 1 & 1 \\
\hline Bulgaria & 1 & 0.58 & 0.47 & 0.58 & 0.47 & 0.81 & 1.49 \\
\hline Czech Republic & 2.67 & 1.06 & 1.01 & 0.40 & 0.38 & 0.95 & 1.65 \\
\hline Denmark & 1.40 & 1.38 & 1.65 & 0.99 & 1.18 & 1.19 & 1.29 \\
\hline Germany & 1 & 1 & 1 & 1 & 1 & 1 & 1 \\
\hline Estonia & 1.84 & 0.99 & 0.94 & 0.54 & 0.51 & 0.95 & 1.40 \\
\hline Ireland & 1 & 1 & 1 & 1 & 1 & 1 & 1 \\
\hline Greece & 0.31 & 0.39 & 0.35 & 1.28 & 1.13 & 0.89 & 1.84 \\
\hline Spain & 1.20 & 1.25 & 0.98 & 1.04 & 0.82 & 0.78 & 1.16 \\
\hline France & 1.49 & 1.33 & 1.64 & 0.89 & 1.10 & 1.23 & 1.31 \\
\hline Croatia & 0.80 & 0.50 & 0.46 & 0.62 & 0.58 & 0.93 & 1.59 \\
\hline Italy & 1.86 & 1.30 & 1.05 & 0.70 & 0.57 & 0.81 & 1.41 \\
\hline Latvia & 0.75 & 0.56 & 0.51 & 0.76 & 0.68 & 0.89 & 1.47 \\
\hline Lithuania & 0.72 & 0.47 & 0.47 & 0.65 & 0.65 & 0.99 & 1.57 \\
\hline Hungary & 1.54 & 0.79 & 0.90 & 0.51 & 0.58 & 1.14 & 1.42 \\
\hline Netherlands & 1 & 1 & 1 & 1 & 1 & 1 & 1 \\
\hline Austria & 1.63 & 1.10 & 1.11 & 0.67 & 0.68 & 1.01 & 1.28 \\
\hline Poland & 0.60 & 0.29 & 0.30 & 0.49 & 0.50 & 1.03 & 2.08 \\
\hline Portugal & 1.29 & 0.88 & 0.94 & 0.68 & 0.73 & 1.06 & 1.22 \\
\hline Romania & 0.31 & 0.14 & 0.11 & 0.44 & 0.37 & 0.83 & 3.40 \\
\hline Slovenia & 1.34 & 0.63 & 0.66 & 0.47 & 0.50 & 1.05 & 1.56 \\
\hline Slovakia & 2.55 & 1.01 & 1.22 & 0.39 & 0.48 & 1.22 & 1.65 \\
\hline Finland & 1.38 & 1.11 & 1.33 & 0.81 & 0.96 & 1.20 & 1.21 \\
\hline Sweden & 0.65 & 0.79 & 0.77 & 1.21 & 1.18 & 0.97 & 1.24 \\
\hline United Kingdom & 0.68 & 0.91 & 0.73 & 1.34 & 1.06 & 0.80 & 1.26 \\
\hline EU-25 ${ }^{\mathrm{a}}$ & 1.10 & 0.91 & 0.89 & 0.83 & 0.81 & 0.98 & 1.13 \\
\hline
\end{tabular}

${ }^{a}$ Indicators of substitution calculated basing on the average for the 25EU economic efficiency indicators of employment in the four sectors 


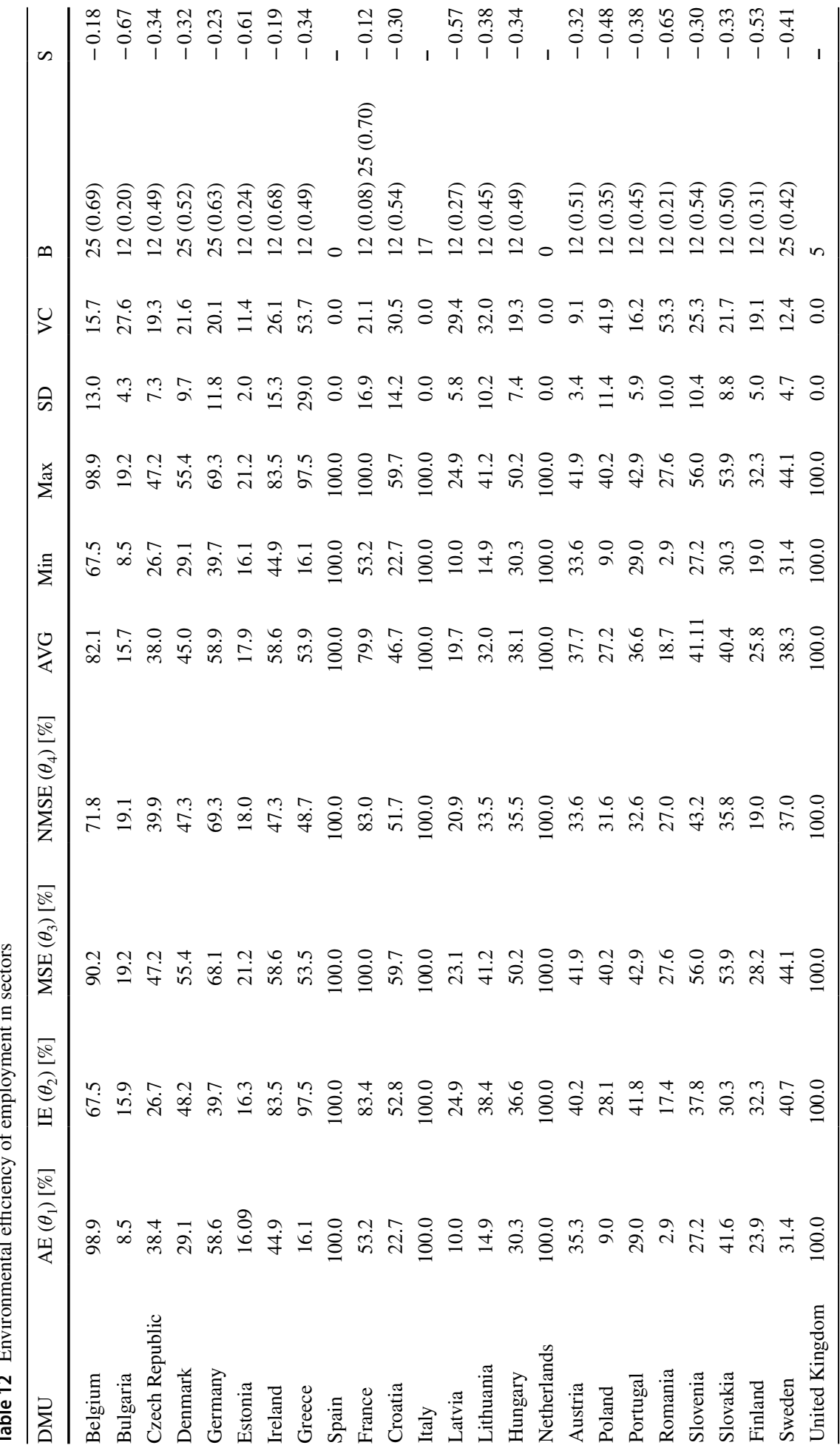




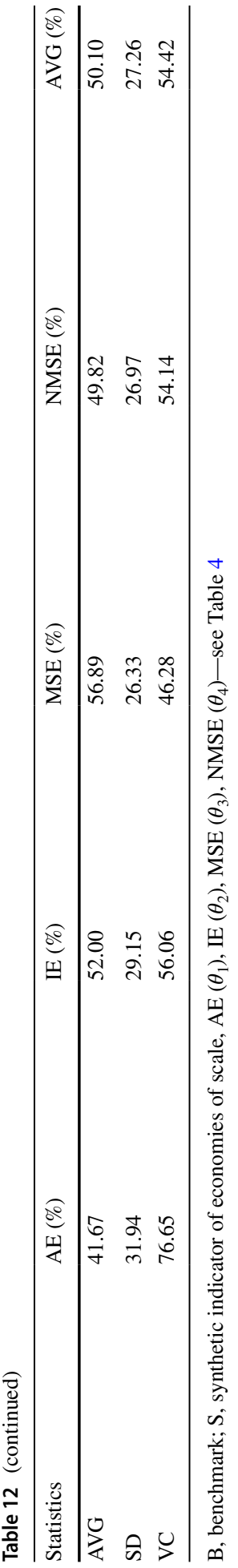

Springer 
Table 13 Detailed indicators of labour inputs substitution between sectors and a synthetic indicator of substitution ( $\mathrm{z}$ - - environmental efficiency optimization

\begin{tabular}{|c|c|c|c|c|c|c|c|}
\hline DMU & $\mathrm{A} / \mathrm{I}$ & $\mathrm{A} / \mathrm{MS}$ & A/NMS & $\mathrm{I} / \mathrm{MS}$ & I/NMS & MS/NMS & $\mathrm{z}$ \\
\hline Belgium & 1.47 & 1.10 & 1.38 & 0.75 & 0.94 & 1.26 & 1.26 \\
\hline Bulgaria & 0.54 & 0.44 & 0.45 & 0.83 & 0.83 & 1.01 & 1.55 \\
\hline Czech Republic & 1.44 & 0.81 & 0.96 & 0.57 & 0.67 & 1.18 & 1.34 \\
\hline Denmark & 0.60 & 0.52 & 0.62 & 0.87 & 1.02 & 1.17 & 1.39 \\
\hline Germany & 1.47 & 0.86 & 0.85 & 0.58 & 0.57 & 0.98 & 1.35 \\
\hline Estonia & 0.99 & 0.76 & 0.89 & 0.77 & 0.90 & 1.18 & 1.17 \\
\hline Ireland & 0.54 & 0.77 & 0.95 & 1.43 & 1.77 & 1.24 & 1.41 \\
\hline Greece & 0.16 & 0.30 & 0.33 & 1.82 & 2.00 & 1.10 & 2.50 \\
\hline Spain & 1 & 1 & 1 & 1 & 1 & 1 & 1 \\
\hline France & 0.64 & 0.53 & 0.64 & 0.83 & 1.01 & 1.21 & 1.37 \\
\hline Croatia & 0.43 & 0.38 & 0.44 & 0.88 & 1.02 & 1.16 & 1.63 \\
\hline Italy & 1 & 1 & 1 & 1 & 1 & 1 & 1 \\
\hline Latvia & 0.40 & 0.43 & 0.48 & 1.08 & 1.19 & 1.11 & 1.60 \\
\hline Lithuania & 0.39 & 0.36 & 0.44 & 0.93 & 1.14 & 1.23 & 1.70 \\
\hline Hungary & 0.83 & 0.60 & 0.85 & 0.73 & 1.03 & 1.42 & 1.29 \\
\hline Netherlands & 1 & 1 & 1 & 1 & 1 & 1 & 1 \\
\hline Austria & 0.88 & 0.84 & 1.05 & 0.96 & 1.20 & 1.25 & 1.14 \\
\hline Poland & 0.32 & 0.22 & 0.28 & 0.70 & 0.89 & 1.27 & 2.16 \\
\hline Portugal & 0.69 & 0.68 & 0.89 & 0.98 & 1.28 & 1.32 & 1.27 \\
\hline Romania & 0.17 & 0.11 & 0.11 & 0.63 & 0.65 & 1.02 & 3.31 \\
\hline Slovenia & 0.72 & 0.49 & 0.63 & 0.67 & 0.87 & 1.30 & 1.47 \\
\hline Slovakia & 1.37 & 0.77 & 1.16 & 0.56 & 0.85 & 1.51 & 1.37 \\
\hline Finland & 0.74 & 0.85 & 1.26 & 1.15 & 1.70 & 1.48 & 1.34 \\
\hline Sweden & 0.77 & 0.71 & 0.85 & 0.92 & 1.10 & 1.19 & 1.21 \\
\hline United Kingdom & 1 & 1 & 1 & 1 & 1 & 1 & 1 \\
\hline $\mathrm{EU}-25^{\mathrm{a}}$ & 0.80 & 0.73 & 0.84 & 0.91 & 1.04 & 1.14 & 1.18 \\
\hline
\end{tabular}

${ }^{a}$ Indicators of substitution calculated basing on the average for the 25EU environmental efficiency indicators of employment in the four sectors 


\section{References}

Ahmed, E. M., \& Krishnasamy, G. (2013). Human capital investment to achieve knowledge-based economy in ASEAN5: DEA applications. Journal of the Knowledge Economy, 4, 331-342.

Andersson, M. P., \& Palacio, A. (2016). Structural change and income inequality-Agricultural development and inter-sectoral dualism in the developing world, 1960-2010. OASIS, 23, 99-122.

Aparicio, J., Cordero, J. M., Gonzalez, M., \& Lopez-Espin, J. J. (2018). Using non-radial DEA to assess school efficiency in a cross-country perspective: An empirical analysis of OECD countries. Omega, 79, 9-20.

Auzina-Emsina, A. (2014). Labour productivity. Economic growth and global competitiveness in post-crisis period. Procedia-Social and Behavioral Sciences, 156, 317-321.

Badunenko, O., \& Romero-Ávila, D. (2014). Productivity growth across Spanish regions and industries: A production-frontier approach. Regional Studies, 48, 1242-1262.

Badunenko, O., \& Romero-Ávila, D. (2015). Productivity growth across industries and regions: A Production-Frontier Approach Applied to the Spanish Case. http://www.alde.es/fotosbd/120620151100331 636.pdf. Accessed June 16, 2018.

Bernard, A. B., \& Jones, C. (1996). Comparing apples to oranges: Productivity convergence and measurement across industries and countries. The American Economic Review, 85, 1216-1238.

Bolis, I., Morioka, S. N., \& Sznelwar, I. (2017). Are we making decisions in a sustainable way? A comprehensive literature review about rationalities for sustainable development. Journal of Cleaner Production, 45, 310-322.

Carree, M. A., Klomp, L., \& Thurik, A. R. (2000). Productivity convergence in OECD manufacturing industries. Economics Letters, 66, 337-345.

Castelli, L., Pesenti, R., \& Ukovich, W. (2010). A classification of DEA models when the internal structure of the decision making units is considered. Annals of Operation Research, 173, 207-235.

Ceccobelli, M., Gitto, S., \& Mancuso, P. (2012). ICT capital and labour productivity growth: A nonparametric analysis of 14 OECD countries. Telecommunications Policy, 36, 282-292.

Charfeddine, L., \& Mrabet, Z. (2017). The impact of economic development and social-political factors on ecological footprint: A panel data analysis for 15 MENA countries. Renewable and Sustainable Energy Reviews, 76, 138-154.

Charnes, A., \& Cooper, W. W. (1962). Programming with fractional function. Naval Research Logistics Quarterly, 9, 181-185.

Charnes, A., Cooper, W. W., \& Rhodes, E. (1978). Measuring the efficiency of decision making units. European Journal of Operational Research, 2(6), 429-444.

Clark, C. (1940). The conditions of economic progress. London: Macmillan and Co., Ltd.

Collins, R. D., Selin, N. E., De Weck, O. L., \& Clark, W. C. (2017). Using inclusive wealth for policy evaluation: Application to electricity infrastructure planning in oil-exporting countries. Ecological Economics, 133, 23-34.

Conceicao, M., Portela, A. S., \& Thanassoulis, E. (2006). Zero weights and non-zero slacks: Different solutions to the same problem. Annals of Operations Research, 145, 129-147.

Cooper, W., Seiford, L., \& Zhu, J. (2011). Data envelopment analysis: History, models, and interpretations. In W. W. Cooper, L. M. Seiford, \& J. Zhu (Eds.), Handbook on data envelopment analysis. International Series in Operations Research \& Management Science (Vol. 164, pp. 1-39). New York: Springer.

Demeter, K., Chika, A., \& Matyusz, Z. (2011). Labour productivity change: Drivers business impact and macroeconomic moderators. International Journal of Production Economics, 131, 215-223.

Dinda, S. (2004). Environmental Kuznets curve hypothesis: A survey. Ecological Economics, 49, 431-455.

Djordjević, B., Krmac, E., \& Mlinarić, T. J. (2018). Non-radial DEA model: A new approach to evaluation of safety at railway level crossings. Safety Science, 103, 234-246.

Färe, R., \& Lovell, C. (1978). Measuring the technical efficiency of production. Journal of Economic Theory, 19(1), 150-162.

Fisher, A. B. G. (1935). The clash of progress and security. London: McMillan.

Fourastié, J. (1949). Le Grand Espoir du XXe siècle. Progrès technique, progrès économique, progrès social. Paris: Presses Universitaires de France.

Freeman, R. (2008). Labour productivity indicators. Comparison of two OECD databases. Productivity differentials \& the Balassa-Samuelson effect. OECD Statistics Directorate. http://www.oecd.org/ employment/labour-stats/41354425.pdf. Accessed January 25, 2017.

Friedman, L., \& Sinuany-Stern, Z. (1997). Scaling units via the canonical correlation analysis in the DEA context. European Journal of Operational Research, 100, 629-637. 
Galdeano-Gómez, E., Pérez-Menza, J. C., \& Godoy-Durán, Á. (2016). The social dimension as a driver of sustainable development: The case of family farms in southeast Spain. Sustainability Science, $11,349-362$.

Gitto, S., \& Mancuso, P. (2015). The contribution of physical and human capital accumulation to Italian regional growth: A nonparametric perspective. Journal of Productivity Analysis, 43, 1-12.

Grossman, G. M., \& Krueger, A. B. (1995). Economic growth and the environment. The Quarterly Journal of Economics, 110(2), 353-377.

Guzik, B. (2009). Podstawowe modele DEA w badaniu efektywności gospodarczej i społecznej. Poznań: University of Economics Publishing.

Halická, M., \& Trnovská, M. (2018). The Russell measure model: Computational aspects, duality, and profit efficiency. European Journal of Operational Research, 268, 386-397.

Halkos, G. E., \& Polemis, M. L. (2018). The impact of economic growth on environmental efficiency of the electricity sector: A hybrid window DEA methodology for the USA. Journal of Environmental Management, 211, 334-346.

Hernández-Sancho, F., Molinos-Senante, M., \& Sala-Garrido, R. (2011). Energy efficiency in Spanish wastewater treatment plants: A non-radial DEA approach. Science of the Total Environment, 409, 2693-2699.

Hirschman, A. O. (1958). The strategy of economic development. New Haven, CT: Yale University Press.

Islam, S. M. N., Munasinghe, M., \& Clarke, M. (2003). Making long-term economic growth more sustainable: Evaluating the costs and benefits. Ecological Economics, 47, 149-166.

Jain, R. K., \& Natarajan, R. (2015). A DEA study of airlines in India. Asia Pacific Management Review, 20, 285-292.

Kiatrungwilaikun, N., \& Suriya, K. (2015). Rethinking inequality and growth: The Kuznets curve after the millennium. International Journal of Intelligent Technologies and Applied Statistics, 8(2), $159-169$.

Ko Li, S. K., \& Zhao, L. (2015). The competitiveness and development strategies of provinces in China: A data envelopment analysis approach. Journal of Productivity Analysis, 44, 293-307.

Kosmalski, R. (2016). Economic convergence in Poland by sector. Wiadomości Statystyczne, 2, 47-61. [in Polish].

Kurt, S., \& Kurt, Ü. (2015). Innovation and labour productivity in BRICS Countries: Panel causality and co-integration. Procedia-Social and Behavioral Sciences, 195, 1295-1302.

Kuznets, S. (1955). Economic growth and income inequality. The American Economic Review, 45, 1-28.

Laurinavičius, E., \& Rimkuvienè, D. (2017). The comparative efficiency analysis of EU members agriculture sectors. Rural Sustainability Research, 37(332), 10-19.

Lee, J.-W. (2005). Human capital and productivity for Korea's sustained economic growth. Journal of Asian Economics, 16, 663-687.

Maggino, F., \& Zumbo, B. D. (2012). Measuring the quality of life and the construction of social indicators. In K. C. Land, et al. (Eds.), Handbook of social indicators and quality of life research (pp. 201-238). New York: Springer. https://doi.org/10.1007/978-94-007-2421-1_10.

Martino, R. (2015). Convergence and growth. Labour productivity dynamics in the European Union. Journal of Macroconomics, 46, 186-200.

Maudos, J., Pastor, J. M., \& Serrano, L. (2000). Efficiency and productive specialization: An application to the Spanish regions. Regional Studies, 34, 829-842.

Misiak, T., Tokarski, T., \& Włodarczyk, R. W. (2011). Convergence or divergence of Polish job markets? Gospodarka Narodowa, 239-240, 47-69. [in Polish].

Nasr, A. B., Balcilar, M., Akadiri, S. S., \& Gupta, R. (2018). Kuznets curve for the US: A reconsideration using cosummability. Social Indicators Research. https://doi.org/10.1007/s11205-018-1940-1.

Nazarko, J., \& Chodakowska, E. (2015). Measuring productivity of construction industry in Europe with data envelopment analysis. Procedia Engineering, 122, 204-212.

O'Leary, E., \& Webber, D. J. (2015). The role of structural change in European regional productivity growth. Regional Studies, 49, 1548-1560.

Our Common Future. (1987). Report of the World Commission on Environment and Development. http://www.un-documents.net/our-common-future.pdf. Accessed April 17, 2017.

Park, K. S. (2010). Duality, efficiency computations and interpretations in imprecise DEA. European Journal of Operational Research, 200, 289-296.

Perroux, F. (1955). Note sur la notion de pôle de criossance. Ekonomie Appliquée, 1-2, 307-320.

Piętak, Ł. (2014). Regional convergence in Spain in 1995-2012. Gospodarka Narodowa, 273, 161-187. [in Polish].

Poveda, A. C. (2011). Economic development and growth in Colombia: An empirical analysis with super-efficiency DEA and panel data models. Socio-Economic Planning Sciences, 45, 154-164. 
Rostow, W. W. (1971). The stages of economic growth: A non-communist manifesto. New York: Cambridge University Press.

Sengupta, J. K. (1990). Test of efficiency in data envelopment analysis. Computers \& Operations Research, 17(2), 123-132.

Tarancón, M.-Á., Gutiérrez-Pedrero, M.-J., Callejas, F. E., \& Martínez-Rodríguez, I. (2018). Verifying the relation between labor productivity and productive efficiency by means of the properties of the input-output matrices. The European case. International Journal of Production Economics, 195, 54-65.

Wong, W.-K. (2006). OECD convergence: A sectoral decomposition exercise. Economic Letters, 93, 210-214.

World Development Indicators. (2016). https://data.worldbank.org. Accessed October 10, 2017.

Woźniak, M. G., Jabłoński, Ł., Soszyńska, E., Firszt, D., \& Bal-Woźniak, T. (2015). Kapitat ludzki w rozwoju innowacyjnej gospodarki i zarzadzaniu innowacyjnościa przedsiębiorstwa. Warszawa: PWE.

Zhou, P., Ang, B. W., \& Poh, K. L. (2008). A survey of data envelopment analysis in energy and environmental studies. European Journal of Operational Research, 189, 1-18. 